\title{
RESEARCH
}

Open Access

\section{Design, statistical optimization of Nizatidine floating tablets using natural polymer}

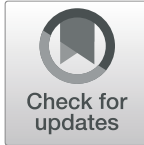

Madhavi Latha Samala ${ }^{*^{*}}$ and Ramesh Babu Janga ${ }^{2}$

\begin{abstract}
Background: The present research was aimed in developing gastroretentive tablets of Nizatidine, in order to increase the bioavailability of the drug. Nizatidine belongs to BCS class 3 and thus formulating into gastroretentive tablets helps to achieve a better therapeutic effect. There were no reports available on the use of Mimosa gum in the design of gastroretentive drug delivery systems. Response surface methodology was employed to optimize the formulation with suitable experimental design. The goal of the response surface methodology was to obtain a regression model and to find a suitable approximation for the true functional relationship between the response and the set of independent variables. Hence, the statistical approach like full factorial design was utilized to obtain optimized formulation with a smaller number of experiments.

Results: DSC study justified no interaction of the drug with excipients. The floating lag time was observed to be less than $20 \mathrm{~s}$, total floating time was in the range of $8-24 \mathrm{~h}$, hardness ranges from 4 to $5 \mathrm{~kg} / \mathrm{cm}^{2}$, and friability was less than $1 \%$. Dissolution data indicated that the higher viscosity of Mimosa (2\%) delayed the drug release for extended period of time up to $23 \mathrm{~h}$ when compared to lower viscosity Mimosa (1\%), which controlled the release of the drug up to $12 \mathrm{~h}$ only. The ' $n$ ' values of all the prepared formulations were found to be 0.59 to 0.81 indicating that the release mechanism followed anomalous (non-Fickian) diffusion. The optimal values of independent test variables were obtained from the overlay plots. The optimized formulation of Mimosa gum (2\%) $(M 2 \%$ opt $)$ contained $170 \mathrm{mg}$ of polymer and $25.5 \mathrm{mg}$ (15\%) of sodium bicarbonate. Similarly, the optimized formulation of Mimosa (1\%) (M1\%opt) contained $255 \mathrm{mg}$ of polymer and $34 \mathrm{mg}(10 \%)$ of sodium bicarbonate.

Conclusion: The results clearly indicated that the optimized formulations followed zero-order release kinetics with diffusion mechanism as per the predicted theoretical release rate confirming the suitability of the predicted theoretical release profile.
\end{abstract}

Keywords: Gastroretentive drug delivery system, Mimosa gum, Nizatidine, Statistical optimization

\footnotetext{
* Correspondence: madhavilatha61@gmail.com

'Department of Pharmaceutics, ANU College of Pharmaceutical Sciences,

Acharya Nagarjuna University, Nagarjuna Nagar, Guntur 522510, India

Full list of author information is available at the end of the article
}

\section{Springer Open}

(c) The Author(s). 2021 Open Access This article is licensed under a Creative Commons Attribution 4.0 International License, which permits use, sharing, adaptation, distribution and reproduction in any medium or format, as long as you give appropriate credit to the original author(s) and the source, provide a link to the Creative Commons licence, and indicate if changes were made. The images or other third party material in this article are included in the article's Creative Commons licence, unless indicated otherwise in a credit line to the material. If material is not included in the article's Creative Commons licence and your intended use is not permitted by statutory regulation or exceeds the permitted use, you will need to obtain permission directly from the copyright holder. To view a copy of this licence, visit http://creativecommons.org/licenses/by/4.0/. 


\section{Background}

The primary objective of gastroretentive drug delivery systems (GRDDS) is to ensure safety of drugs as well as patient compliance. Gastric floating tablets have less density than gastric fluid and consequently they are able to float in the stomach for prolonged period of time releasing the drug slowly at the required rate from the system which results an elevated gastric retention time.

In the present study, Nizatidine [1] was selected as drug of choice to design the effervescent gastric floating matrix tablets (EGFMT) [2-4] using Mimosa gum [5-7] as a matrix forming polymer.

EGFMT of Nizatidine were designed to retain the tablets in the stomach for longer periods of time and deliver Nizatidine effectively to the absorption window for maintaining the effective plasma levels for a prolonged time thereby decreasing the frequency of administration of drug. Nizatidine is a histamine $\mathrm{H}_{2}$ receptor antagonist used to treat and prevent the recurrence of ulcers and occasional heartburn, acid indigestion, or sour stomach. It decreases the amount of acid made in the stomach.

Many naturally available polymers [8] were being studied for their future prospects in the development of prolonged active ingredient release. It was observed that there was difference in properties from one batch to the other when natural excipients were used. The observed changes were due to change in the physicochemical properties. Hence in the present investigation, the properties of Mimosa gum were evaluated and its applicability in the design of floating tablets was studied.

One of the statistical optimization techniques, response surface methodology (RSM), was utilized for the development and optimization of EGFMT. RSM was employed to observe the empirical relationship between one or more measured responses and a number of independent variables in the form of polynomial equations, mapping of the response over the experimental domain, with the ultimate goal of obtaining an optimal formulation [9-11].

\section{Methods and materials}

\section{Materials}

Nizatidine was received as a gift sample from Aurobindo Pharma (Hyderabad, India). Mimosa gum was kindly provided by Govt. Co-operative stores (Mumbai). Sodium bicarbonate was provided as gift sample from Kartikeya Chemicals. (Hyderabad, India). All other chemicals and solvents were of analytical grade or highest quality and were used as such as obtained.

\section{Methods}

\section{Physicochemical characterization of mimosa gum}

Mimosa seed gum hydrates well and swells swiftly when comes in contact with water. Mimosa gum has greatest advantage of degrading into biologically acceptable molecules that are easily metabolized and removed from the body. It sustains the release of drug from the dosage form by following diffusion mechanism at higher proportions. For this reason, it was selected for the present study.

The physiochemical properties of Mimosa gum such as particle size distribution, surface characteristics, bulk density, tapped density, compressibility, moisture content, $\mathrm{pH}$, volatile acidity, swelling, and water absorption properties were measured $[12,13]$.

\section{Preparation of tablets}

All the ingredients sufficient for a batch of 100 tablets according to the formulae shown in Tables 1 and 2 were passed through \#30 mesh $(600 \mu \mathrm{m})$. Active ingredient was mixed geometrically with specified excipients in order to get a uniform blend and the produced blend was lubricated with magnesium stearate and aerosil and compressed into tablets on a 16 station rotary tablet punching machine $(\mathrm{M} / \mathrm{s}$. Cadmach Minipress Machinery Co. Pvt. Ltd, India) using $12 \mathrm{~mm}$ round, flat, plain punches using sufficient compression force to obtain a hardness of 4 to $5 \mathrm{~kg} / \mathrm{cm}^{2}$ containing $85 \mathrm{mg}$ of Nizatidine per tablet.

\section{Evaluation of tablets}

In vitro floating characteristics So far, prepared tablets of Nizatidine were studied for floating lag time (FLT) and total floating time (TFT). FLT and TFT were determined for 3 tablets of each batch in the $1 \mathrm{~L}$ glass beaker containing $900 \mathrm{ml}$ of $0.1 \mathrm{~N} \mathrm{HCl}$ [14].

Table 1 Formulae of Nizatidine EGFMT using Mimosa gum (2\%)

\begin{tabular}{|c|c|c|c|c|c|c|c|c|c|}
\hline Ingredients (mg/tablet) & FNM1 & FNM2 & FNM3 & FNM4 & FNM5 & FNM6 & FNM7 & FNM8 & FNM9 \\
\hline Nizatidine & 85 & 85 & 85 & 85 & 85 & 85 & 85 & 85 & 85 \\
\hline Mimosa gum (2\%) high viscosity & 85 & 85 & 85 & 170 & 170 & 170 & 255 & 255 & 255 \\
\hline Sodium bicarbonate & 17 & 25.5 & 34 & 25.5 & 38.25 & 51 & 34 & 51 & 68 \\
\hline Aerosil & 2 & 2 & 2 & 3 & 3 & 3 & 4 & 4 & 4 \\
\hline Magnesium stearate & 1 & 1 & 1 & 1 & 1 & 1 & 1 & 1 & 1 \\
\hline
\end{tabular}


Table 2 Formulae of Nizatidine EGFMT using Mimosa gum (1\%)

\begin{tabular}{llllllllll}
\hline Ingredients (mg/tablet) & FNW1 & FNW2 & FNW3 & FNW4 & FNW5 & FNW6 & FNW7 & FNW8 & FNW9 \\
\hline Nizatidine & 85 & 85 & 85 & 85 & 85 & 85 & 85 & 85 & 85 \\
Mimosa gum (1\%) Low viscosity & 85 & 85 & 85 & 170 & 170 & 170 & 255 & 255 & 255 \\
Sodium bicarbonate & 17 & 25.5 & 34 & 25.5 & 38.25 & 51 & 34 & 51 & 68 \\
Aerosil & 2 & 2 & 2 & 3 & 3 & 3 & 4 & 4 & 4 \\
Magnesium stearate & 1 & 1 & 1 & 1 & 1 & 1 & 1 & 1 \\
\hline
\end{tabular}

Swelling index The drug release from any tablet depends upon the \% of intake of medium; here, the medium used was $0.1 \mathrm{~N} \mathrm{HCl}$. The medium temperature was maintained at $37 \pm 0.5^{\circ} \mathrm{C}$ throughout the study.

$$
\begin{gathered}
\text { Swelling index }(\text { S.I })=\left\{\left(W_{\mathrm{t}}-W_{\mathrm{O}}\right) / W_{\mathrm{O}}\right\} \times 100 \\
\text { Where S.I }=\text { Swelling index } \\
W_{\mathrm{t}}=\text { Weight of swollen tablet } \\
W_{\mathrm{O}}=\text { Initial weight of tablet }
\end{gathered}
$$

Uniformity of weight test As per official pharmacopeia, 20 tablets were taken in random, studied for difference in weight both individually and in group. The mean and percent deviations were determined [15].

Hardness test The strength of each tablet was measured using tablet hardness tester (Monsanto type, MHT-20). The mean hardness was determined and expressed in $\mathrm{kg} / \mathrm{cm}^{2}$. Five tablets were taken to perform the above phenomenon [16].

Friability test The friability test was carried out in Roche Friabilator (PANOMEX Inc., PX/FTA-201). The tablets equivalent to weight of $6.5 \mathrm{~g}$ were selected randomly and initial weight $\left(w_{\mathrm{o}}\right)$ was noted down after de-dusting and placed in a rotating drum. They were subjected to 100 falls of 6 in height (25 rpm for $4 \mathrm{~min}$ ) [17]. The percent loss in weight (or friability) was calculated by the formula given below.

$$
f=\left(1-\frac{w}{w_{0}}\right) \times 100
$$

Uniformity of content test To study this, 10 tablets were taken and crushed; from this, $50 \mathrm{mg}$ was taken in to the volumetric flask. The drug was extracted into $25 \mathrm{ml}$ of $0.1 \mathrm{~N} \mathrm{HCl}$ with vigorous shaking on a mechanical shaker for $1 \mathrm{~h}$ and the volume was made up to the mark with $0.1 \mathrm{~N} \mathrm{HCl}$. The solution was filtered through $0.45 \mu \mathrm{m}$ Millipore nylon filter disc and appropriate dilutions were further made with 0.1
$\mathrm{N} \mathrm{HCl}$. The dilutions were measured for the absorbance by UV spectrophotometer (UV-1800, Shimadzu, Japan) at $325 \mathrm{~nm}$ against blank $(0.1 \mathrm{~N} \mathrm{HCl})$. Content of each individual preparations were determined and the average of 10 was calculated.

In vitro drug release studies The drug release from the prepared floating tablets was studied using USP XXIV dissolution rate test apparatus (LABINDIA). Then, $900 \mathrm{ml}$ of $0.1 \mathrm{~N} \mathrm{HCl}$ was used as dissolution medium maintained at a temperature of $37 \pm 0.5{ }^{\circ} \mathrm{C}$ and the paddle was rotated at $50 \mathrm{rpm}$. The procedure was studied and the samples were suitably diluted and the absorbance was measured by UV spectrophotometer (UV-1800, Shimadzu, Japan) at $325 \mathrm{~nm}$. Drug release from commercial release formulation of Nizatidine was also studied.

\section{Comparison of dissolution data}

The differences in the rate and extent of drug release due to formulation and process variables can be studied by model independent and model dependent approaches [18-21].

Model independent approaches Model independent approaches are based on dissolution efficiency (DE) or on mean dissolution time (MDT) or on time to release certain percentage of drug like $T_{\mathrm{X}}$ (time to release $\mathrm{X} \%$ of drug), difference factor $\left(f_{1}\right)$, and similarity factor $\left(f_{2}\right)$, etc.

In the present investigation, three responses; floating lag time $\left(Y_{1}\right)$, swelling index at first hour $\left(Y_{2}\right)$, and time to release $100 \%$ of drug $\left(T_{100}\right)\left(Y_{3}\right)$ were studied.

Another model independent approach is based on comparing the similarities of experimental formulations with reference formulation. Comparing the parameters obtained similar to methods proposed by Moore and Flanner which involves calculation of $f_{1}$ and $f_{2}$. The $f_{1}$ and $f_{2}$ were calculated using the equations given below.

$$
\mathrm{f} 2=50 * \log \left\{\left[1+(1 / \mathrm{n}) \sum_{j=1}\left(\mathrm{R}_{\mathrm{j}}-\mathrm{T}_{\mathrm{j}}\right)^{2}\right]^{-0.5 *} 100\right\}
$$




$$
\begin{aligned}
& j=\mathrm{n} \quad j=\mathrm{n} \\
& f 1=\left[\sum\left(R_{\mathrm{j}}-T_{\mathrm{j}}\right) / \sum R_{\mathrm{j}}\right] * 100 \\
& j=1 \quad j=1
\end{aligned}
$$

where $n$ is sampling number, $R_{\mathrm{j}}$ and $T_{\mathrm{j}}$ are respectively $\%$ drug dissolved from reference and experimental formulations at time $j[22,23]$.

Model dependent approaches The order of drug release from matrix systems was described by using zeroorder [24] or first -order kinetics [25, 26]. The mechanism of drug release from matrix systems was studied by using Higuchi diffusion model [27] and Hixon-Crowell erosion model [28]. Korsemeyer-Peppas [29, 30] support the drug release mechanism for further judgments.

\section{Data analysis, optimization, and cross-validation of model}

Data analysis DESIGN EXPERT (Stat-Ease Inc., Minneapolis, USA) software was used for analyzing the data. It selects and suggests the highest order polynomial model as a suitable model based on coefficient of determination $\left(R^{2}\right)$ and predicted residual sum of squares (PRESS) values where the additional terms are significant. Analysis of variance (ANOVA) was performed on the suggested model for the responses $Y_{1}, Y_{2}$, and $Y_{3}$ to identify significant effect.

Multiple regression analysis was performed on the dependent variables to know the significance of the regression coefficients on the model. The models generated were used to construct contour (2D) and response surface (3D) plots for floating lag time, swelling index at first hour, and time to release $100 \%$ of drug responses of Mimosa gum (2\%) and Mimosa gum (1\%) based formulations to understand the main and the interaction effects of these three factors [31-33].

Optimization Desirability and graphical optimization technique (overlay plots) were employed to optimize the formulations with the desired responses (responses from theoretical profile values).

Optimization was performed with constraints of $Y_{1}$ Floating lag time $=9 \mathrm{~s}, Y_{2}$ swelling index at first hour $=16 \%$, and $Y_{3}$ time to release $100 \%$ of drug $=16.2 \mathrm{~h}$, which were obtained from the theoretical profile. For finalizing the optimum formulation, targets were set for these constraints for getting respective desirability function response and overlay plots.

Cross-validation of model Optimized EGFMT of FNM ${ }_{\text {opt }}$ and $\mathrm{FNW}_{\text {opt }}$ were evaluated for uniformity of weight, hardness, friability, uniformity of content, in vitro floating, and in vitro dissolution. Pictures were taken for optimized formulations during in vitro floating. The $f_{1}$ and $f_{2}$ values were determined for optimized formulations using theoretical release profile as reference formulation.

The experimental values of the responses (floating lag time, swelling index at first hour, and time to release $100 \%$ of drug) were determined from the in vitro dissolution data of the optimized EGFMT.

The percentage relative error between predicted values and experimental values of each response was calculated using the below equation.

\section{Drug-polymer interaction studies}

Fourier transform infrared spectroscopy Fourier transform infrared spectroscopy (FTIR) spectra of samples were obtained on a Perkin Elmer 2000 FTIR system (PerkinElmer, Norwalk, CT) using the $\mathrm{KBr}$ disk method (2 mg sample in $200 \mathrm{mg} \mathrm{KBr})$. The scanning range was $450-4000$ $\mathrm{cm}^{-1}$ and the resolution were $1 \mathrm{~cm}^{-1}$.

Differential scanning calorimetry Differential scanning calorimetry (DSC) was performed using a differential scanning calorimeter (DSC 220C, Seiko, Japan) at a heating rate of $10{ }^{\circ} \mathrm{C} / \mathrm{min}$ from 30 to $300{ }^{\circ} \mathrm{C}$ in nitrogen atmosphere.

Table 3 Characterization of Mimosa gum

\begin{tabular}{ll}
\hline Property & Results obtained \\
Tapped density (g/cc) & $0.702 \pm 0.02$ \\
Bulk density (g/cc) & $0.632 \pm 0.04$ \\
Bulkiness (cc/g) & $1.58 \pm 0.04$ \\
Angle of repose $\left(^{\circ}\right)$ & $28.20 \pm 1.28$ \\
Compressibility index (\%) & $10.42 \pm 1.34$ \\
Hausner's ratio & $1.2 \pm 1.54$ \\
pH & $4.8 \pm 0.20$ \\
Water retention capacity & $19 \pm 1.67$ \\
Swelling index (\%) & $120 \pm 10.00$ \\
Volatile acidity (\%) & $17.2 \pm 2.98$ \\
Moisture content & $14.96 \pm 1.12$ \\
Property & Results obtained \\
Tapped density (g/cc) & $0.702 \pm 0.02$ \\
Bulk density (g/cc) & $0.632 \pm 0.04$ \\
Bulkiness (cc/g) & $1.58 \pm 0.04$ \\
Angle of repose ( ${ }^{\circ}$ ) & $28.20 \pm 1.28$ \\
Compressibility index (\%) & $10.42 \pm 1.34$ \\
Hausner's ratio & $1.2 \pm 1.54$ \\
pH & $4.8 \pm 0.20$ \\
Water retention capacity & $19 \pm 1.67$ \\
Swelling index (\%) & $120 \pm 10.00$ \\
Volatile acidity (\%) & $17.2 \pm 2.98$ \\
Moisture content & $14.96 \pm 1.12$ \\
\hline
\end{tabular}


Table 4 Angle of repose $(\theta)$ values of Drug- Polymer physical mixtures

\begin{tabular}{|c|c|c|c|c|}
\hline \multirow{2}{*}{$\begin{array}{l}\text { Drug: } \\
\text { Polymer } \\
\text { Ratio }\end{array}$} & \multicolumn{2}{|l|}{ Mimosa gum(2\%) } & \multicolumn{2}{|l|}{ Mimosa gum(1\%) } \\
\hline & Angle of repose $(\theta)$ & Inference & Angle of repose $(\theta)$ & Inference \\
\hline \multicolumn{5}{|c|}{ Nizatidine } \\
\hline 1:0 & $52.1^{\circ}$ & Poor & $52.1^{\circ}$ & Poor \\
\hline $1: 1$ & $29.2^{0}$ & Good & $32.4^{0}$ & Passable \\
\hline $1: 2$ & $27.7^{0}$ & Good & $28.2^{0}$ & Good \\
\hline $1: 3$ & $24.9^{\circ}$ & Excellent & $25.5^{\circ}$ & Excellent \\
\hline
\end{tabular}

X-ray diffraction studies X-ray diffraction patterns of powdered samples were recorded on a Philips powder X-ray diffractometer (with Philips, PW 1140/90 X-ray generator) using $\mathrm{Ni}$-filtered, $\mathrm{CuK} \alpha$ radiation, at $45 \mathrm{KV}$ and $25 \mathrm{~mA}$ between 5 and $60^{\circ} 2 \theta$ values with $2^{\circ} / 2 \mathrm{~cm} /$ $2 \theta$ chart speed.

\section{Results}

Physicochemical characterization of mimosa gum

The physicochemical properties of gum are shown in Table 3.

\section{Flow properties}

Nizatidine showed an angle of repose value of $52.1^{\circ}$ indicating poor flow and flow characteristics changed to excellent flow with increase in polymer content. The results of angle of repose values of all drug-polymer physical mixtures are represented in Table 4.

\section{In vitro floating characteristics}

In the present work, EGFMT were designed using hydrophilic polymer (Mimosa gum) and a gas generating agent (sodium bicarbonate). Mimosa is a low-density hydrophilic polymer, rapidly hydrates, and produces hydrogel to control the drug release. Upon contact with gastric contents, sodium bicarbonate in the tablets liberates carbon dioxide which is entrapped in hydrocolloid causes a decrease in the density and results an upward movement of the dosage form and keeps it afloat. The results of in vitro floating behavior of EGFMT are summarized in Table 5.

Table $\mathbf{5}$ In vitro floating properties and tabletting characteristics of Nizatidine EGFMT

\begin{tabular}{|c|c|c|c|c|c|c|}
\hline EGMFT & FLT (s) & TFT (h) of weighta & Uniformity of weight ${ }^{a}$ & Uniformity content ${ }^{\mathrm{b}}(\%)$ & Hardness ${ }^{\mathrm{c}}\left(\mathrm{kg} / \mathrm{cm}^{2}\right)$ & Friability (\%) \\
\hline FNM1 & 9 & 14 & $190.0 \pm 1.97$ & $102.92 \pm 1.05$ & $4-5$ & 0.06 \\
\hline FNM2 & 5 & 13 & $198.5 \pm 2.91$ & $99.44 \pm 1.34$ & $4-5$ & 0.13 \\
\hline FNM3 & 2 & 12 & $207 \pm 1.42$ & $101.4 \pm 1.45$ & $4-5$ & 0.17 \\
\hline FNM4 & 14 & 18 & $284.5 \pm 1.34$ & $98.24 \pm 1.76$ & $4-5$ & 0.09 \\
\hline FNM5 & 8 & 18 & $297.25 \pm 0.4$ & $96.52 \pm 0.09$ & $4-5$ & 0.14 \\
\hline FNM6 & 6 & 16 & $310.0 \pm 0.98$ & $99.64 \pm 0.47$ & $4-5$ & 0.03 \\
\hline FNM7 & 18 & 24 & $379.0 \pm 1.56$ & $98.64 \pm 0.97$ & $4-5$ & 0.15 \\
\hline FNM8 & 13 & 24 & $396.0 \pm 1.45$ & $99.82 \pm 1.57$ & $4-5$ & 0.19 \\
\hline FNM9 & 8 & 24 & $413.0 \pm 1.31$ & $97.12 \pm 1.85$ & $4-5$ & 0.17 \\
\hline FNW1 & 5 & 8 & $190.1 \pm 1.23$ & $99.95 \pm 1.48$ & $4-5$ & 0.08 \\
\hline FNW2 & 3 & 8 & $198.5 \pm 1.75$ & $103.40 \pm 0.15$ & $4-5$ & 0.16 \\
\hline FNW3 & 1 & 8 & $207.0 \pm 0.93$ & $101.52 \pm 1.57$ & $4-5$ & 0.19 \\
\hline FNW4 & 7 & 11 & $284.5 \pm 0.2$ & $99.92 \pm 1.49$ & $4-5$ & 0.17 \\
\hline FNW5 & 5 & 10 & $297.25 \pm 1.6$ & $97.30 \pm .049$ & $4-5$ & 0.18 \\
\hline FNW6 & 4 & 10 & $310.0 \pm 1.24$ & $99.66 \pm 0.15$ & $4-5$ & 0.06 \\
\hline FNW7 & 13 & 13 & $379.0 \pm 0.97$ & $99.92 \pm 1.43$ & $4-5$ & 0.01 \\
\hline FNW8 & 10 & 12 & $396.0 \pm 0.98$ & $97.60 \pm 1.46$ & $4-5$ & 0.03 \\
\hline FNW9 & 5 & 12 & $413.0 \pm 1.46$ & $99.74 \pm 1.54$ & $4-5$ & 0.15 \\
\hline
\end{tabular}

FLT floating lag time, TFT total floating time

${ }^{\mathrm{a}}$ Mean $\pm \%$ deviation, $n=20$

${ }^{\mathrm{b}}$ Mean \pm s.d., $n=10$

${ }^{\mathrm{c}}$ Mean, $n=5$ 

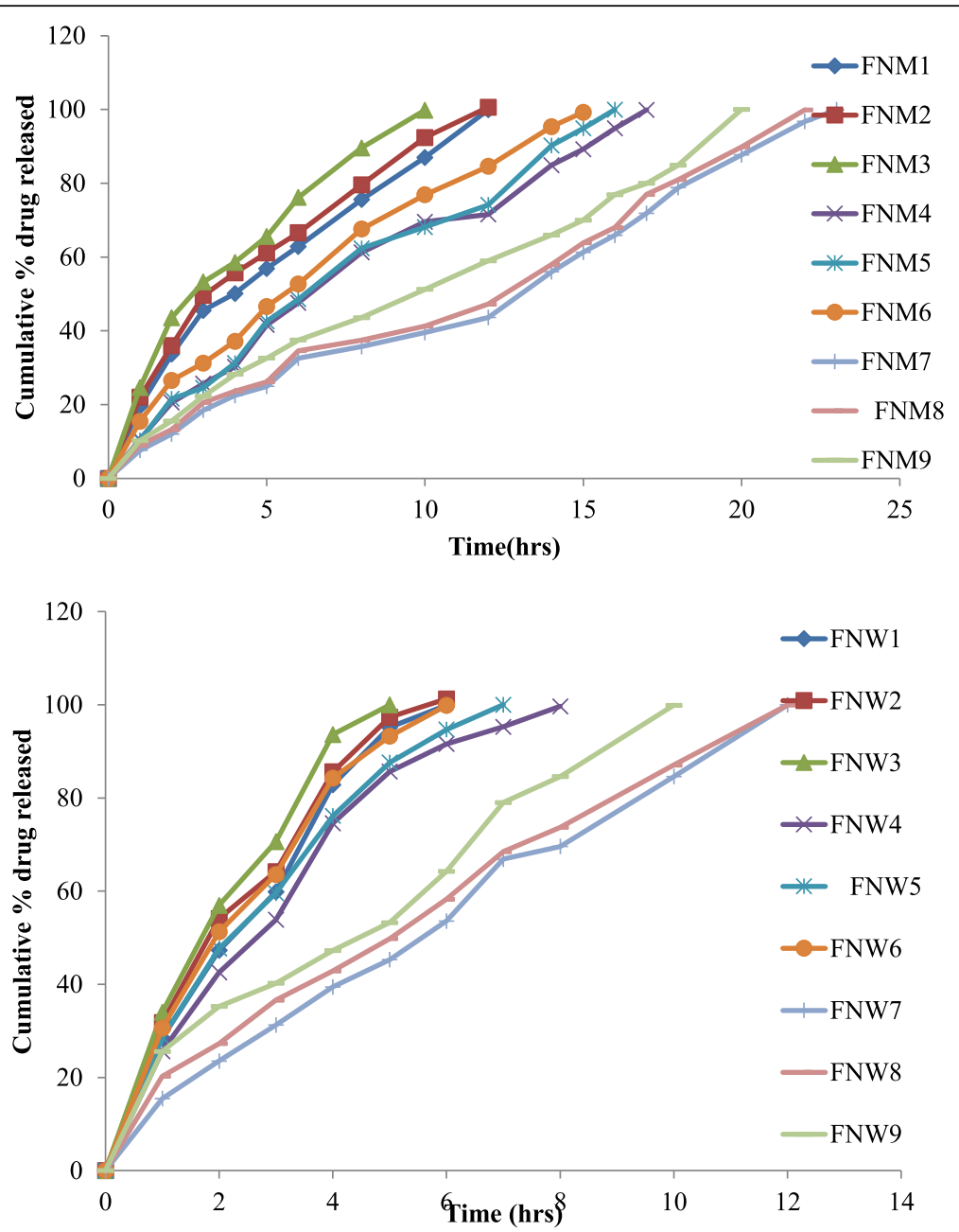

Fig. 1 Dissolution profiles of Mimosa gum (2\%), (1\%) based EGFMT

Table $6 T_{100}$ values of the EGFMT

\begin{tabular}{llll}
\hline EGFMT & $\boldsymbol{T}_{\mathbf{1 0 0}}(\mathbf{h})$ & EGFMT & $\boldsymbol{T}_{\mathbf{1 0 0}}(\mathbf{h})$ \\
\hline FNM1 & 12 & FNW1 & 6 \\
FNM2 & 12 & FNW2 & 6 \\
FNM3 & 10 & FNW3 & 5 \\
FNM4 & 17 & FNW4 & 8 \\
FNM5 & 16 & FNW5 & 7 \\
FNM6 & 15 & FNW6 & 6 \\
FNM7 & 23 & FNW7 & 12 \\
FNM8 & 22 & FNW8 & 12 \\
FNM9 & 20 & FNW9 & 10 \\
\hline
\end{tabular}

The floating lag time was observed to be less than $20 \mathrm{~s}$ for all the prepared formulations. Total floating time was observed to be in the range of 8-24 h.

\section{Uniformity of weight, hardness, friability, and uniformity of content}

The results of uniformity of weight, hardness, friability, and uniformity of content are represented in Table 5.

\section{In vitro drug release studies}

The percent of Nizatidine released data of Mimosa (2\%) and Mimosa (1\%) based EGFMT drug release profiles are shown respectively in Fig. 1.

The results indicated slow and controlled release of Nizatidine from Mimosa (2\%) and Mimosa (1\%) based EGFMT. During the first hour, the \% drug released values were found to be in the range of $7-25 \%$ from the Mimosa (2\%) based EGFMT and 15-34\% from Mimosa (1\%). The drug release was extended from 10 to $23 \mathrm{~h}$ for Mimosa (2\%) formulations. About 100\% 


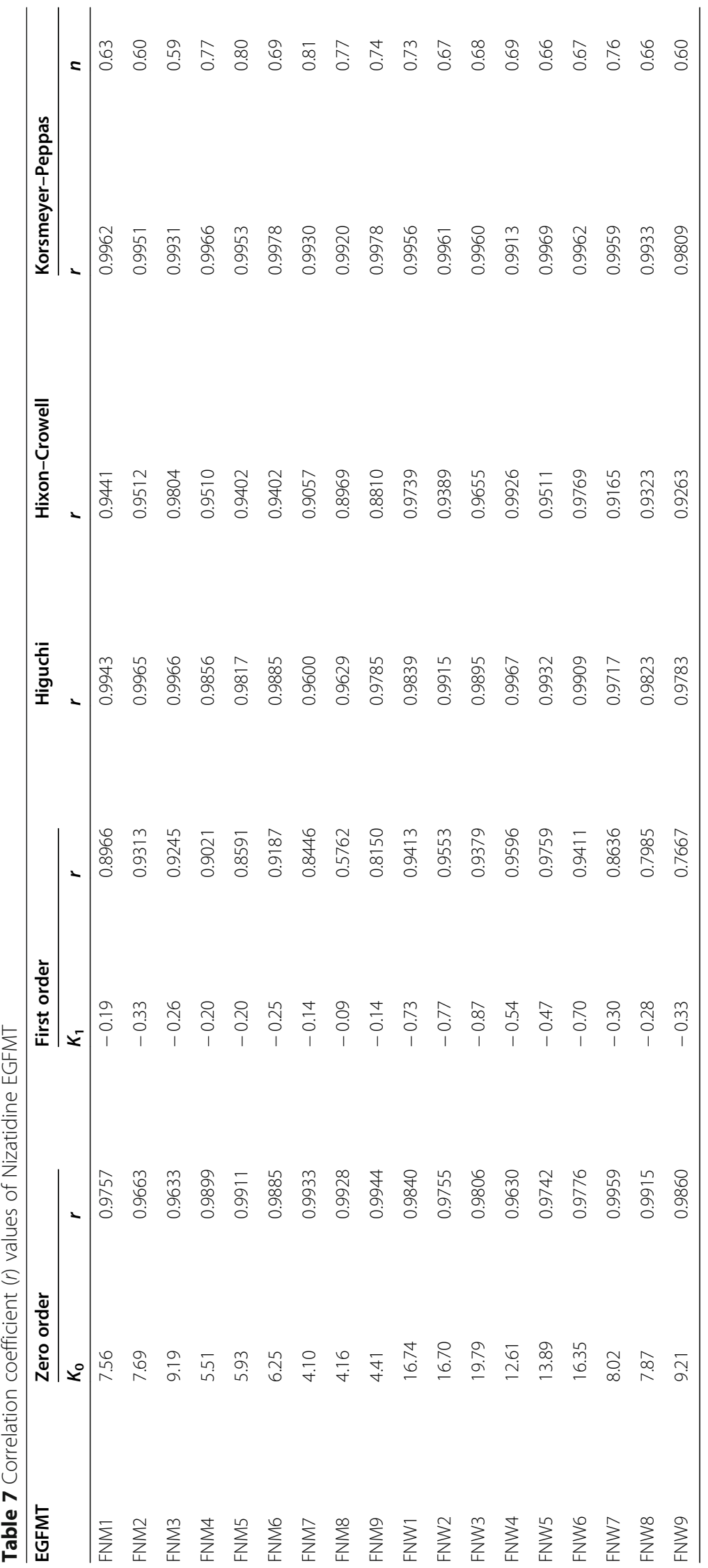




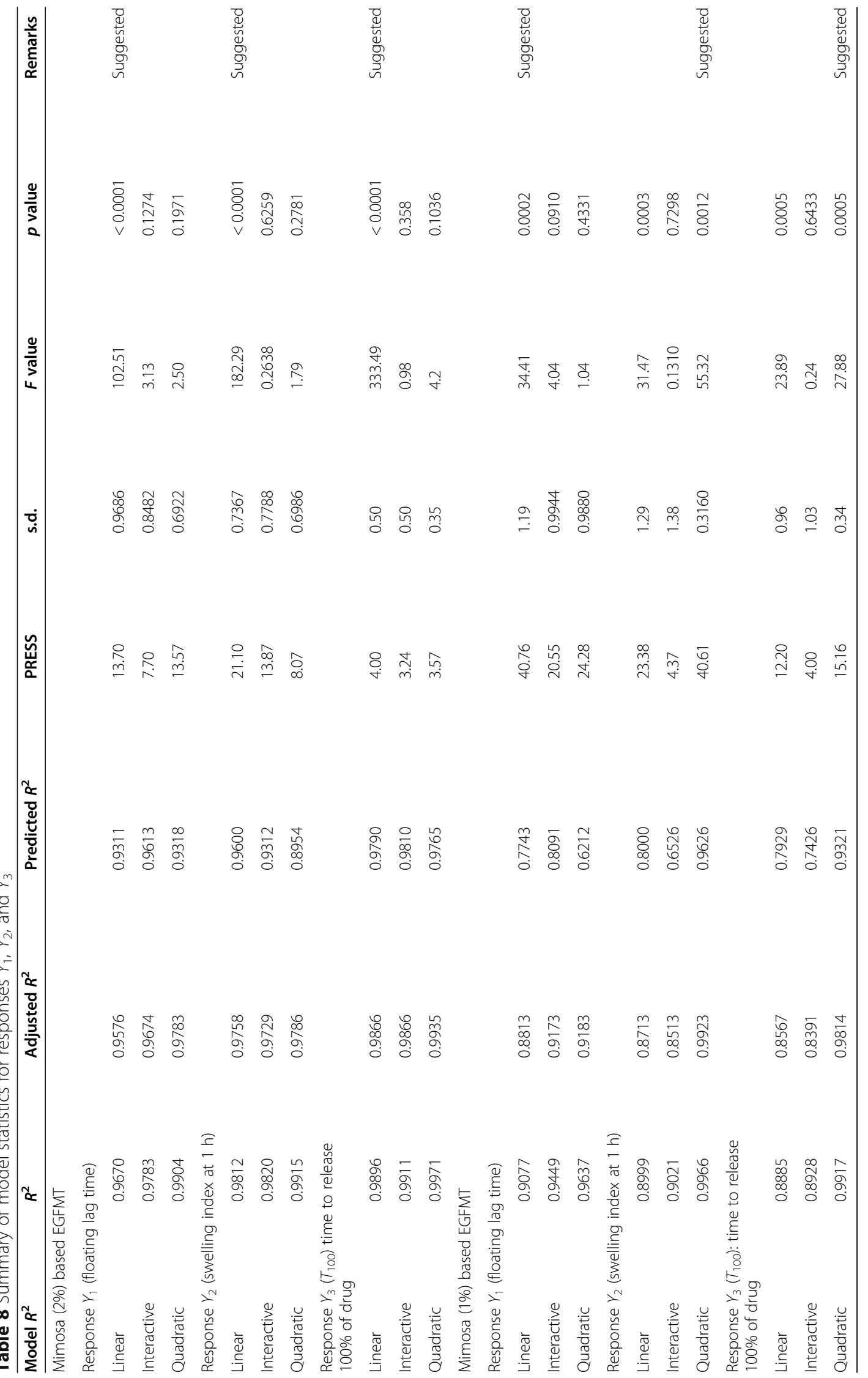


Table 9 ANOVA for the responses of Mimosa 2\% and 1\% based EGFMT

\begin{tabular}{|c|c|c|c|c|c|}
\hline Source & SS & df & MS & $F$ value & $p$ value \\
\hline \multicolumn{6}{|c|}{ Mimosa $2 \%$-response $Y_{1}$ (linear model) } \\
\hline Model & 192.33 & 2 & 96.17 & 102.51 & $<0.0001^{*}$ \\
\hline$X_{1}$-Mimosa $2 \%$ & 88.17 & 1 & 88.17 & 93.98 & $<0.0001^{*}$ \\
\hline$X_{2}$-Sodium bicarbonate & 104.17 & 1 & 104.17 & 111.04 & $<0.0001^{*}$ \\
\hline Residual & 6.57 & 7 & 0.9381 & & \\
\hline Total & 198.90 & 9 & & & \\
\hline \multicolumn{6}{|c|}{ Response $Y_{2}$ (linear model) } \\
\hline Model & 197.88 & 2 & 98.94 & 182.29 & $<0.0001^{*}$ \\
\hline$X_{1}-$ Mimosa $2 \%$ & 92.04 & 1 & 92.04 & 169.58 & $<0.0001^{*}$ \\
\hline$X_{2}$-Sodium bicarbonate & 105.84 & 1 & 105.84 & 195.00 & $<0.0001^{*}$ \\
\hline Residual & 3.80 & 7 & 0.5428 & & \\
\hline Total & 201.68 & 9 & & & \\
\hline \multicolumn{6}{|c|}{ Response $Y_{3}$ (linear model) } \\
\hline Model & 168.33 & 2 & 84.17 & 333.4 & $<0.0001^{*}$ \\
\hline$X_{1}$-Mimosa $2 \%$ & 160.17 & 1 & 160.17 & 634.6 & $<0.0001^{*}$ \\
\hline$X_{2}$-Sodium bicarbonate & 8.17 & 1 & 8.17 & 32.4 & $0.0007^{*}$ \\
\hline Residual & 1.77 & 7 & 0.28 & & \\
\hline Total & 170 & 9 & & & \\
\hline \multicolumn{6}{|c|}{ Mimosa 1\%-response $Y_{1}$ (linear model) } \\
\hline Model & 97.67 & 2 & 48.83 & 34.41 & 0.0002 \\
\hline$X_{1}$-Mimosa $1 \%$ & 60.17 & 1 & 60.17 & 42.20 & 0.0003 \\
\hline$X_{2}$-Sodium bicarbonate & 37.50 & 1 & 37.50 & 26.43 & 0.0013 \\
\hline Residual & 9.93 & 7 & 1.42 & & \\
\hline Total & 107.60 & 9 & & & \\
\hline \multicolumn{6}{|c|}{ Response $Y_{2}$ (quadratic model) } \\
\hline Model & 116.50 & 5 & 23.30 & 233.29 & $<0.0001^{*}$ \\
\hline$X_{1}-$ Mimosa $1 \%$ & 8.40 & 1 & 8.40 & 84.12 & 0.0008 \\
\hline$X_{2}$-Sodium bicarbonate & 96.80 & 1 & 96.80 & 969.17 & $<0.0001^{*}$ \\
\hline$x_{1} x_{2}$ & 0.2500 & 1 & 0.2500 & 2.50 & $0.1888^{* *}$ \\
\hline$X_{1} X_{1}$ & 0.0430 & 1 & 0.0430 & 0.4303 & $0.5477^{* *}$ \\
\hline$x_{2} x_{2}$ & 10.93 & 1 & 10.93 & 109.43 & 0.0005 \\
\hline Residual & 0.3995 & 4 & 0.0999 & & \\
\hline Total & 116.90 & 9 & & & \\
\hline \multicolumn{6}{|c|}{ Response $Y_{3}$ (quadratic model) } \\
\hline Model & 58.41 & 5 & 11.68 & 95.74 & $0.0003^{*}$ \\
\hline$X_{1}$-Mimosa $1 \%$ & 48.17 & 1 & 48.17 & 394.73 & $0.0001^{*}$ \\
\hline$X_{2}$-Sodium bicarbonate & 4.17 & 1 & 4.17 & 34.51 & 0.004 \\
\hline$x_{1} x_{2}$ & 0.25 & 1 & 0.25 & 2.05 & $0.22^{* *}$ \\
\hline$x_{1} x_{1}$ & 5.76 & 1 & 5.76 & 47.22 & 0.0023 \\
\hline$x_{2} X_{2}$ & 0.428 & 1 & 0.428 & 3.51 & $0.1342^{* *}$ \\
\hline Residual & 0.4881 & 4 & 0.122 & & \\
\hline Total & 58.90 & 9 & & & \\
\hline
\end{tabular}


of the drug was released from FNM1 to FNM9 in 12, $12,10,17,16,15,23,22$, and $20 \mathrm{~h}$ respectively. Almost all the drug (>99\%) was released from the Mimosa (1\%) formulations in 5-12 h.

$T_{100}$ values were determined as model independent approaches and summarized in Table 6 and they were found to be in the range of $10-23 \mathrm{~h}$ and $5-12 \mathrm{~h}$ for Mimosa (2\%) and Mimosa (1\%) based formulations respectively and results are shown in Table 6.

\section{Model dependent approaches Drug release kinetics}

The zero- and first-order correlation coefficient $(r)$ values of EGFMT are presented in Table 6. In all the cases, the appropriate correlation coefficient $(r)$ values were in favor of zero-order release rather than first order release.

\section{Drug release mechanisms}

The correlation coefficient $(r)$ values of Higuchi, HixonCrowell and Korsmeyer-Peppas models are represented in Table 7. It was found that EGFMT prepared with both the percentages of Mimosa gum showed predominating diffusion mechanism than erosion mechanism as indicated by higher correlation coefficient values of Higuchi model.

Plots of log fraction of Nizatidine released versus log time of all EGFMT were found to be linear. The ' $r$ ' values of these matrices were found to be 0.9809 to 0.9978 indicating that the release followed Korsmeyer-Peppas model also. The exponential ' $n$ ' values of all the prepared formulations were found to be 0.59 to 0.81 indicating that the release mechanism followed anomalous (non-Fickian) diffusion, i.e., the polymer swelling and polymer and drug dissolution governs the drug release from the matrix. This behavior indicating that the release of the drug depends simultaneously on the matrix swelling and diffusion phenomena.

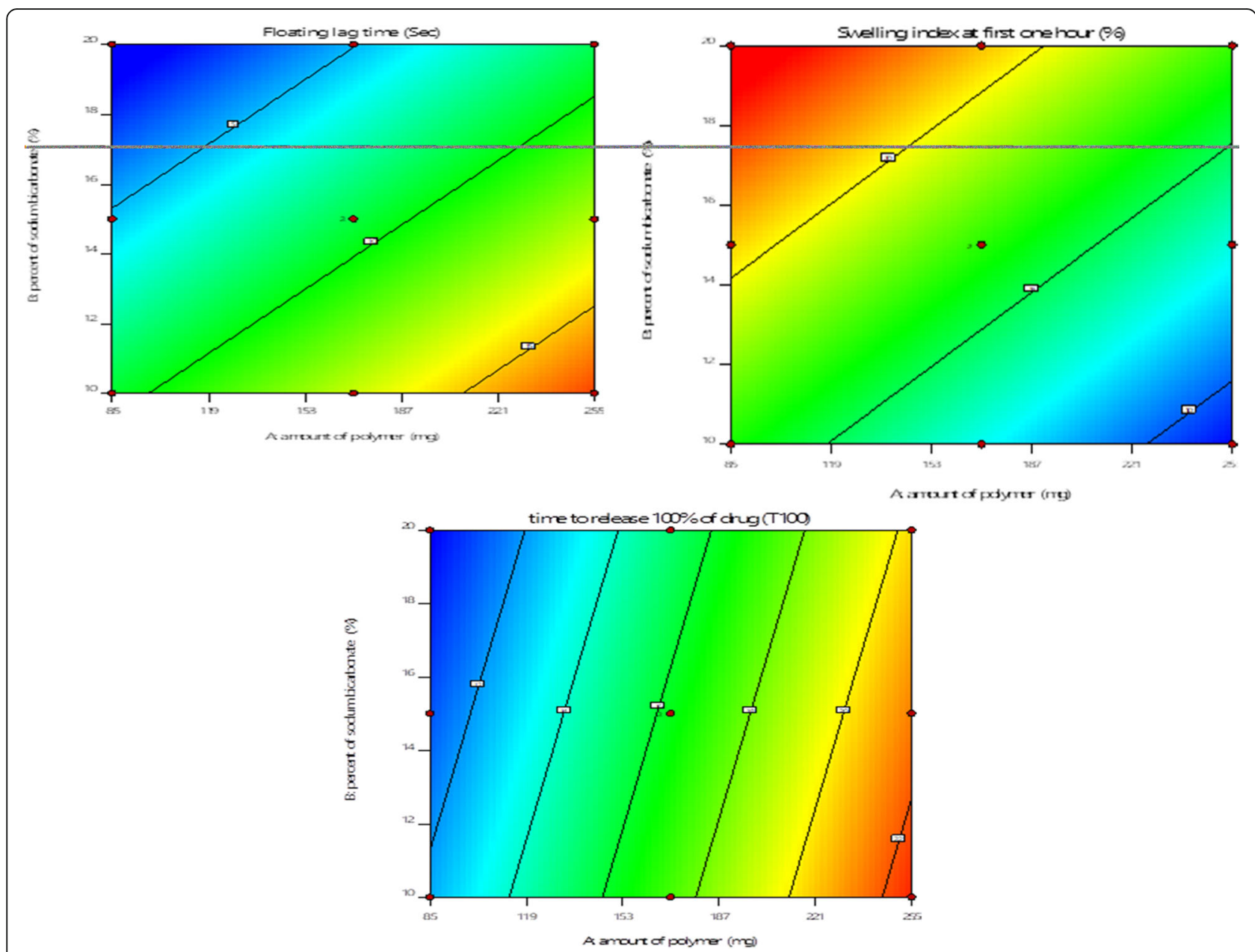

Fig. 2 Contour plot showing the influence of Mimosa gum (2\%) $\left(X_{1}\right)$ and sodium bicarbonate $\left(X_{2}\right)$ on Floating lag time $(s)$, swelling index at first $1 \mathrm{~h}(\%)$, and time to release $100 \%$ of drug $\left(T_{100}\right)$ 
Data analysis, optimization, and cross-validation of model Data analysis

Three responses, i.e., $Y_{1}$ (floating lag time), $Y_{2}$ (swelling index at $1 \mathrm{~h})$, and $Y_{3}\left(T_{100}\right)$ were selected for statistical optimization and fitted to linear, interactive, and quadratic models. The summary of statistics was presented in Table 7 and the comparative $R^{2}$, adjusted $R^{2}$, predicted $R^{2}$, PRESS, s.d., $F$ values, and $p$ values were determined using DESIGN EXPERT (Stat-Ease Inc., Minneapolis, USA). A suitable polynomial model for describing the data was selected based on correlation $\left(R^{2}\right)$ and PRESS values. Response $Y_{1}$, response $Y_{2}$, and response $Y_{3}$ followed linear model for Mimosa (2\%) based EGFMT. Quadratic models were followed by responses $Y_{2}$ and $Y_{3}$ respectively for Mimosa (1\%) based EGFMT, whereas linear model was followed by $Y_{1}$.

The results of the second-order response surface model fitting in the form of ANOVA are given in Table 8 respectively for Mimosa (2\%) and (1\%) based formulations. These parameters were used to construct the independent variables on the responses.

The $F$ value for the responses, floating lag time $\left(Y_{1}\right)$, swelling index at $1 \mathrm{~h}\left(Y_{2}\right)$, and $T_{100}\left(Y_{3}\right)$ were found to be $102.51,182.29$, and 333.4 respectively for Mimosa $2 \%$ based EGFMT and 34.41, 233.29, and 95.74respectively for Mimosa 1\% based EGFMT, which indicated that the models were significant. The values of Prob $>F$ (less than

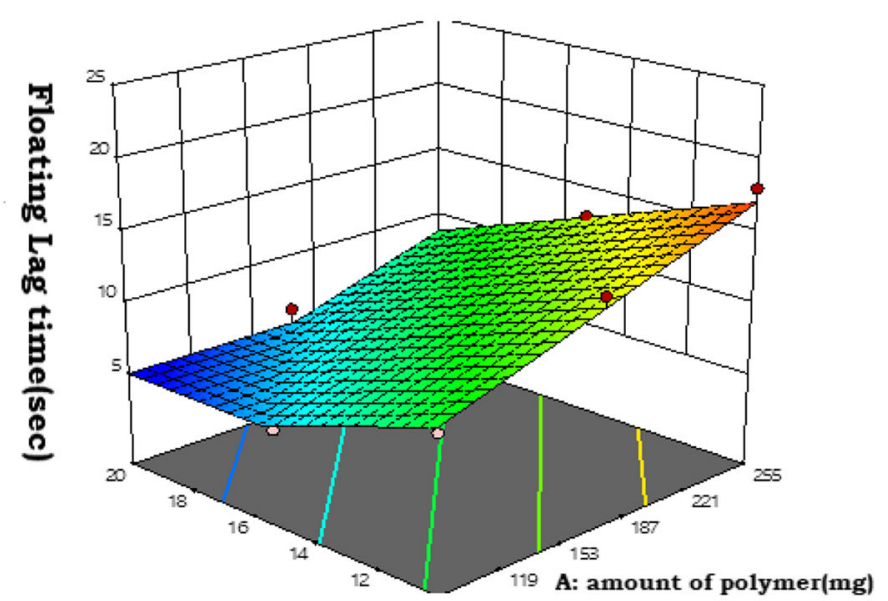

B: Percent of sodiumbicarbonate(\%)

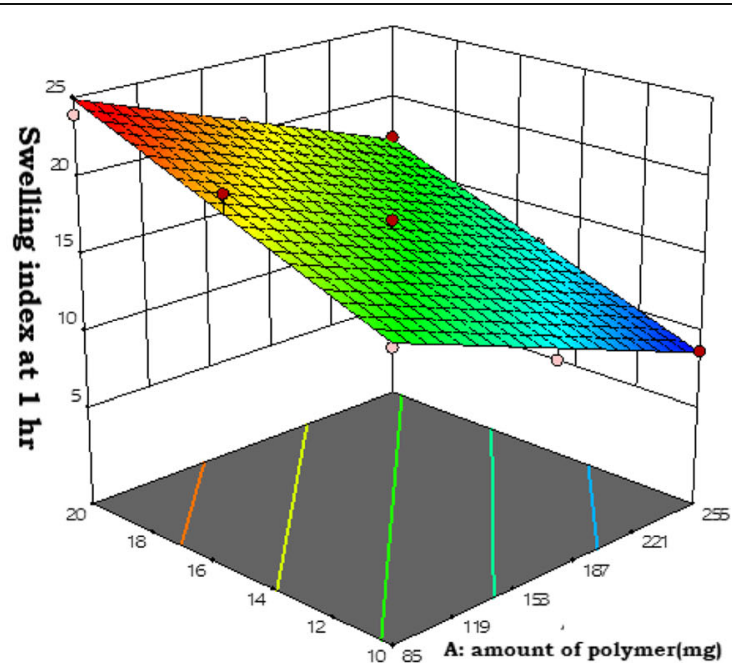

B: Percent of sodiumbicarbonate(\%)

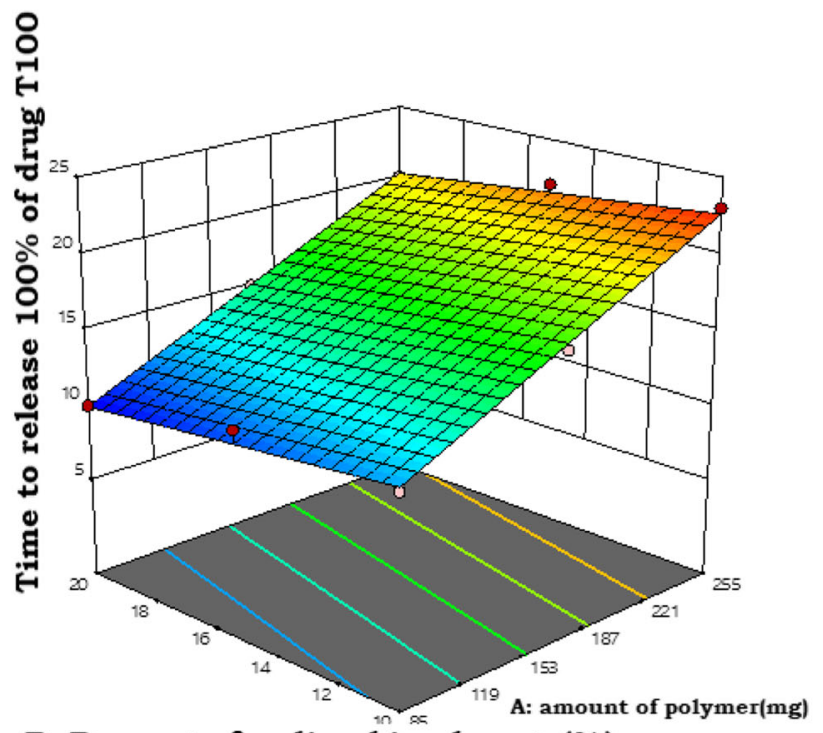

B: Percent of sodiumbicarbonate $(\%)$

Fig. 3 Response surface plot showing the influence of Mimosa gum (2\%) $\left(X_{1}\right)$ and sodium bicarbonate $\left(X_{2}\right)$ on FLT (s), SWI (\%), and $T_{100}$ 
0.05) for all the responses indicated the significance of the models.

The goodness of fit of the model was checked by the coefficient of determination $\left(R^{2}\right)$. The $R^{2}$ values of floating lag time $\left(Y_{1}\right)$, swelling index at $1 \mathrm{~h}\left(Y_{2}\right)$, and $T_{100}$ (Y3) responses of Mimosa $2 \%(0.9670,0.9812$, and 0.9896 respectively) and Mimosa $1 \%$ (0.9077, 0.9966, and 0.9917 respectively) based formulations indicated a good correlation between the independent and dependent variables. The model was found to be significant with respect to adjusted coefficient of determination (Adj $R^{2}$ $>0.9000$ ) values for both polymers. In all the cases,
'Predicted $R^{2}$ ' values were in reasonable agreement with the Adj $R^{2}$ values.

The application of response surface methodology yielded the following regression equations which are an empirical relationship between the logarithm values of $\% \mathrm{DR} 1$ and $T_{100}$.

For Mimosa 2\% based EGFMT:

Floating lag time $=9.10+3.83 X_{1}-4.17 X_{2}$

Swelling index at $1 \mathrm{~h}=16.77-3.92 \mathrm{X}_{1}+4.20 \mathrm{X}_{2}$
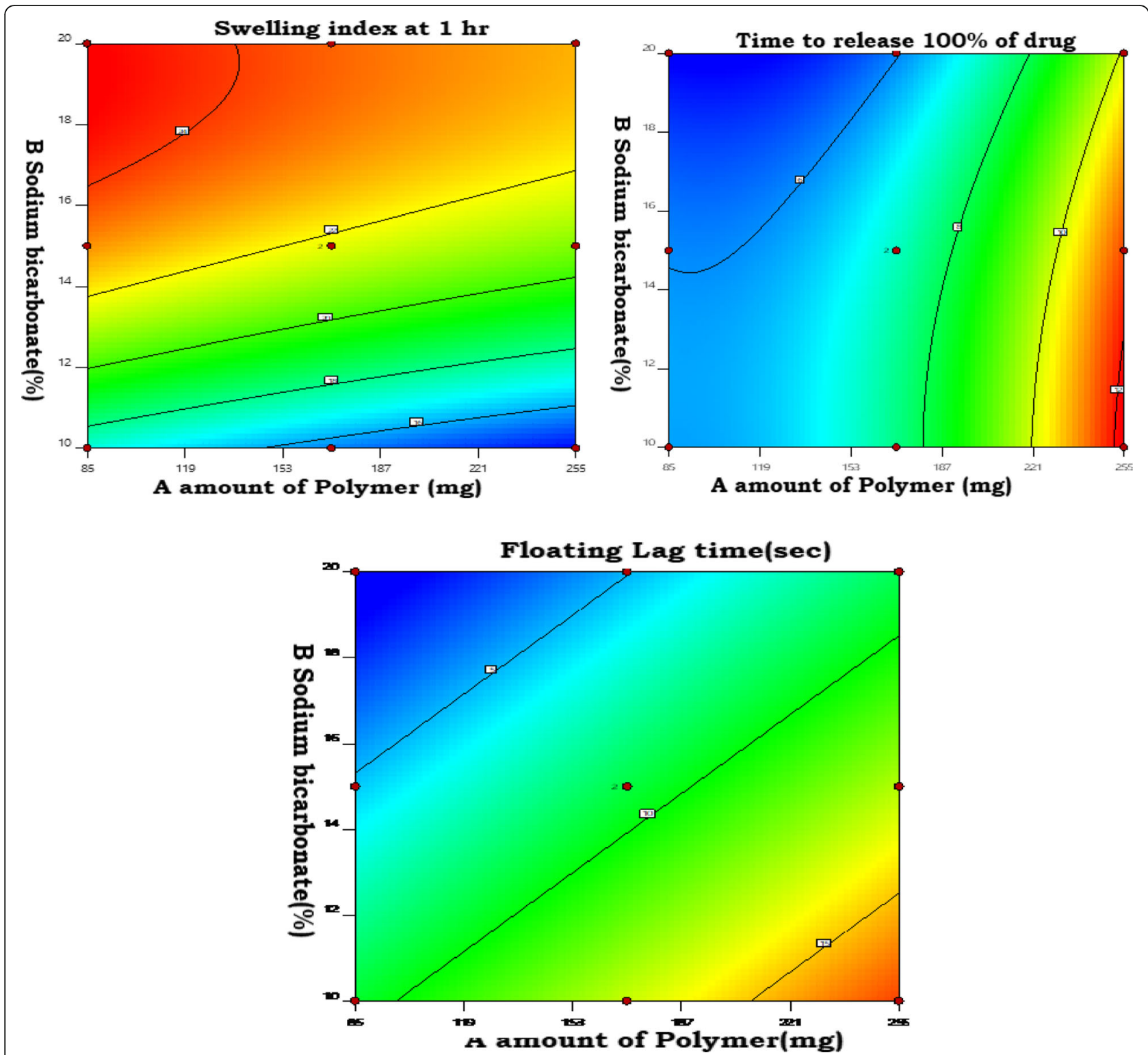

Fig. 4 Contour plot showing the influence of Mimosa gum (1\%) $\left(X_{1}\right)$ and sodium bicarbonate $\left(X_{2}\right)$ on floating lag time $(s)$, swelling index at $1 \mathrm{~h}$, and time to release $100 \%$ of drug 
$T_{100}=16.33+5.17 \mathrm{X}_{1}-1.17 \mathrm{X}_{2}$

For Mimosa 1\% based EGFMT:

Floating lag time $=6.9667+0.037255 X_{1}-0.50000 X_{2}$

Swelling index at $1 \mathrm{~h}=21.76-1.18 X_{1}+4.02 X_{2}+0.2500 X_{1} X_{2}$ $+0.1357 X_{1} X_{1}-2.16 X_{2} X_{2}-3.11$

$$
\begin{aligned}
T_{100}= & 7.21+2.83 X_{1}-0.83 X_{2}-0.25 X_{1} X_{2} \\
& +1.57 X_{1} X_{1}-0.43 X_{2} X_{2}
\end{aligned}
$$

where $X_{1}$ and $X_{2}$ are the coded values of the test variables of the polymer quantity and $\% \mathrm{w} / \mathrm{w}$ of sodium bicarbonate respectively.
The detailed summary of results of multiple regression analysis of dependant variables for both polymer grades is shown in Table 10.

The contour plots were built to evaluate the relationship between polymer content and \% of sodium bicarbonate and their effect on formulation parameters such as FLT, SWI, and $T_{100}$ for both Mimosa 2\% and Mimosa 1\% based EGFM $\mathrm{T}$ (Figs. 2, 3, and 4). Similarly, response surface plots were generated to determine the role of effect of polymer content and $\%$ of sodium bicarbonate on FLT, SWI, and $T_{100}$ for both Mimosa 2\% and 1\% based EGFMT (Figs. 3 and 5).

\section{Optimization}

The higher desirability value indicates the more suitability of the formulation and the optimized formula can directly

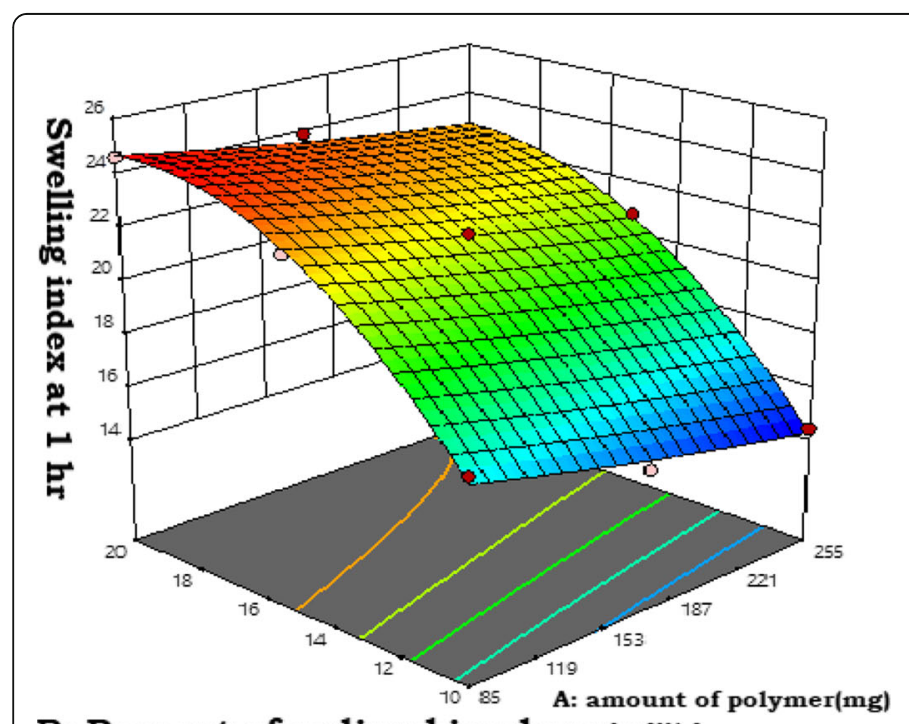

B: Percent of sodiumbicarbonate $(\%)$

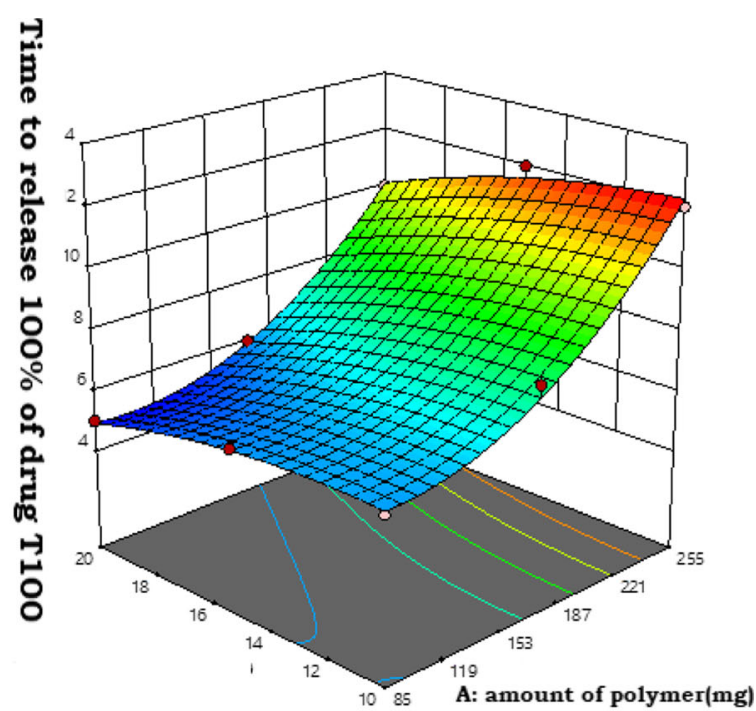

B: Percent of sodiumbicarbonate(\%)

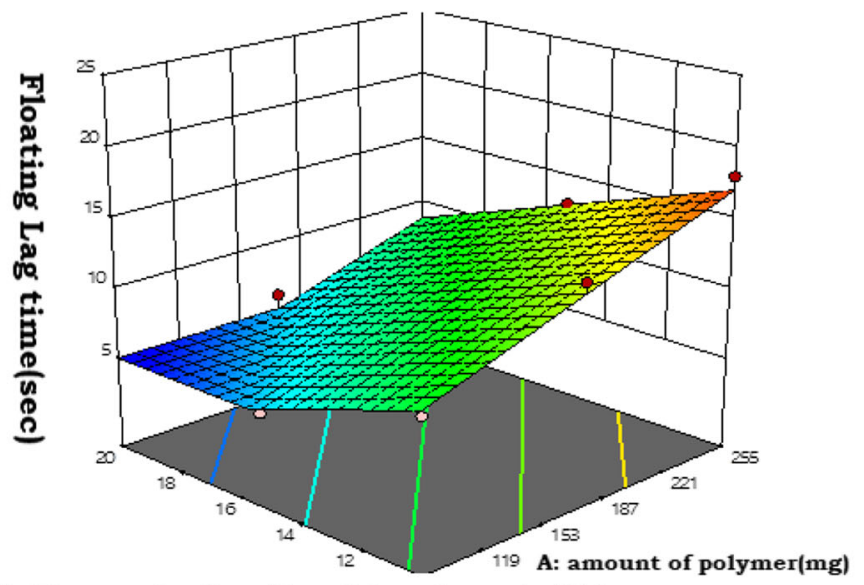

B: Percent of sodiumbicarbonate(\%)

Fig. 5 Response surface plot showing the influence of Mimosa gum (1\%) $\left(X_{1}\right)$ and sodium bicarbonate $\left(X_{2}\right)$ on floating lag time $(s)$, swelling index at first $1 \mathrm{~h}(\%)$, and time to release $100 \%$ of drug $\left(T_{100}\right)$ 

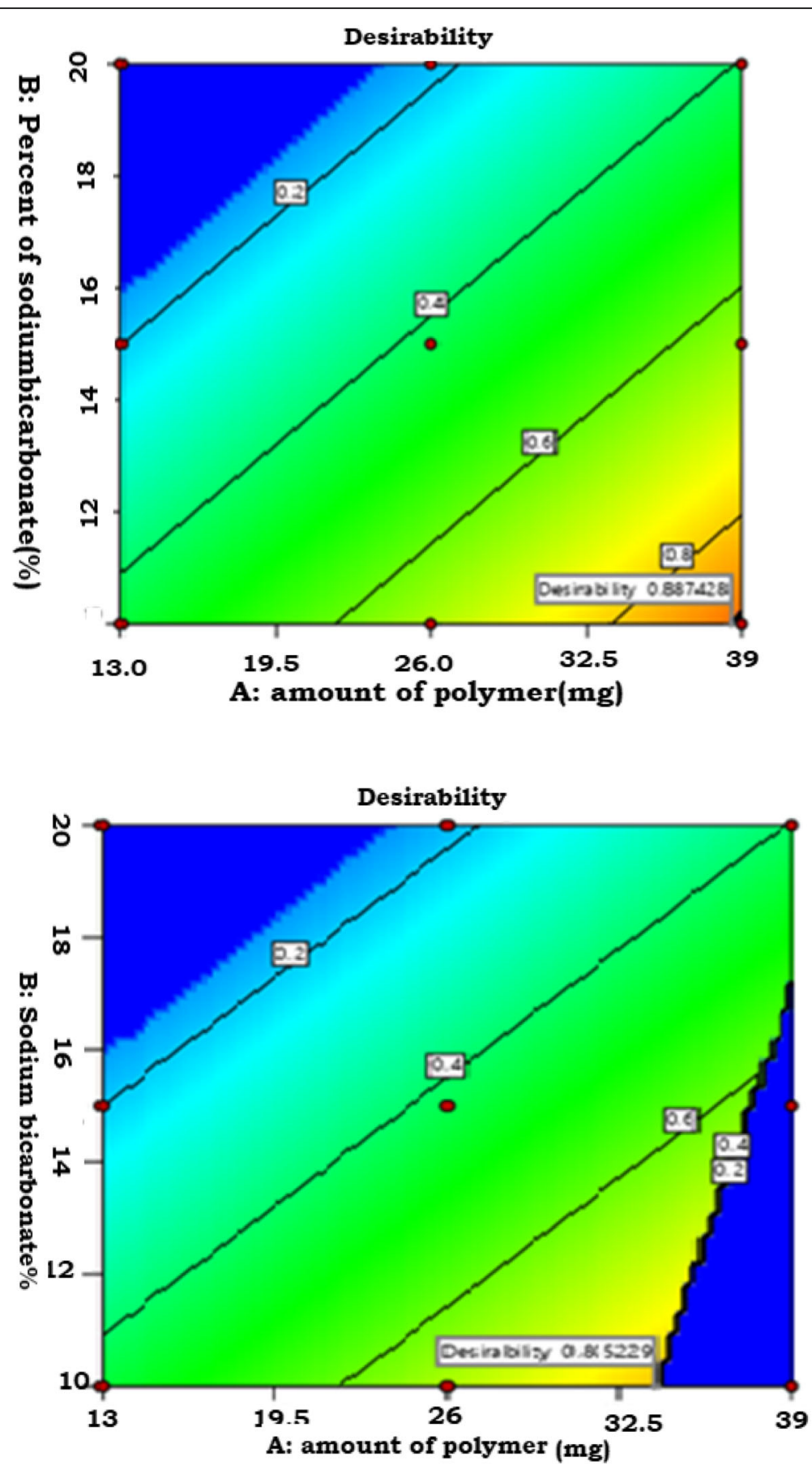

Fig. 6 Desirability plot for Mimosa gum (2\%), (1\%) based EGFMT

be obtained from the desirability function response surface plots and (or) overlay plots. The desirability function (as shown in Fig. 6) was found to be higher (near to 0.9) for the optimized formula indicating the suitability of the formulations. The optimal values of independent test variables were obtained from the overlay plots (Fig. 7).

\section{Cross-validation of model}

The model predicted that the formulation with floating lag time $9.1 \mathrm{~s}$, swelling index at $1 \mathrm{~h}$ is $16.77 \%$ and $T_{100}$ in $12 \mathrm{~h}$ can be obtained using the above optimum concentrations. Hence, formulations were prepared with the above optimized concentrations of polymer and sodium 
Floating lag time
Swelling Index at first hour time to release $100 \%$ of ding $\mathrm{x}_{2}=\mathrm{B}$ : percent of sodium bicarbonate

Floating lag time Swelling Index at first hour time to release $100 \%$ of $d$ tro

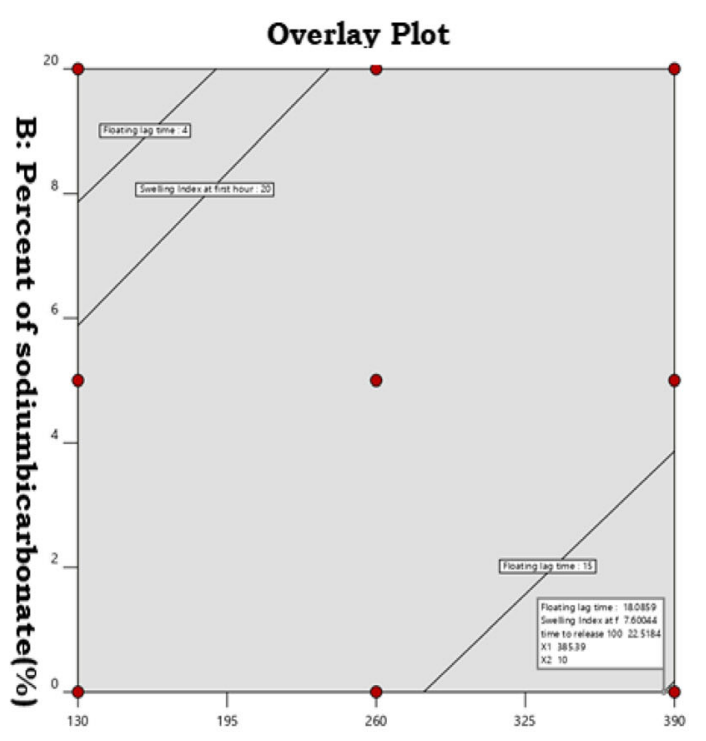

A: amount of polymer(mg)

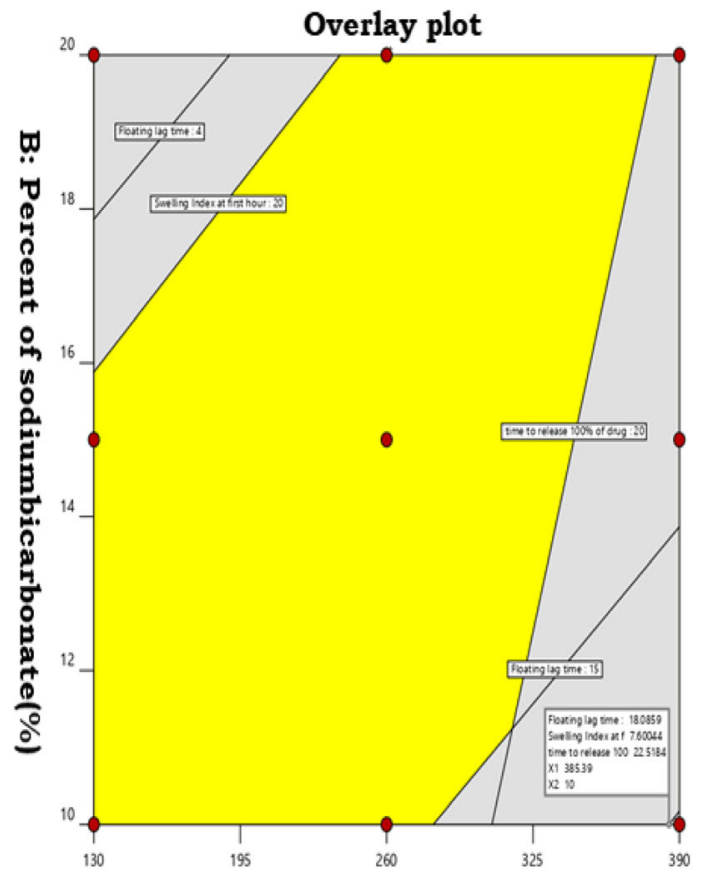

A: amount of polymer(mg)

Fig. 7 Overlay plot for Mimosa gum (2\%),(1\%) based EGFMT

bicarbonate with other ingredients viz. Aerosil and magnesium stearate. The prepared optimized EGFMT fulfilled all the evaluation tests described and the results are shown in Table 11. The floating lag time for $M(2 \%)$ opt was found to be $9.1 \mathrm{~s}$ and that of $M(1 \%)$ opt was found to be $10.3 \mathrm{~s}$. Both the optimized formulations floated up to $14 \mathrm{~h}$ and $13 \mathrm{~h}$ respectively for $M 2 \%$ opt and $M 1 \%_{\text {opt }}$.
The dissolution data of optimized EGFMT is represented and comparative dissolution profiles of the optimized EGFMT and theoretical release profile is shown in Fig. 8.

The correlation coefficient values of release order kinetics and release mechanism models along with $f_{1}$ and $f_{2}$ values are presented in Table 12 . 


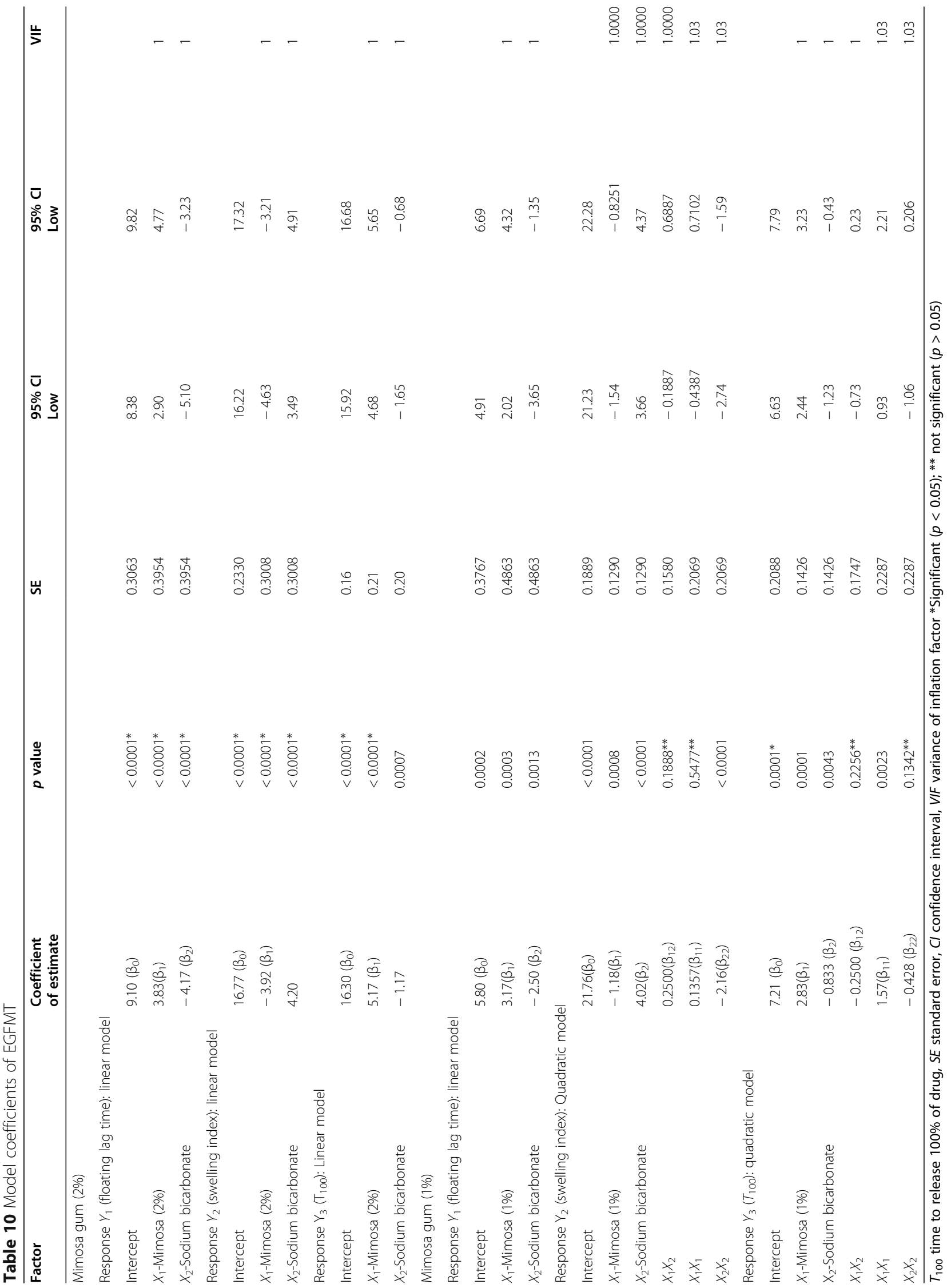




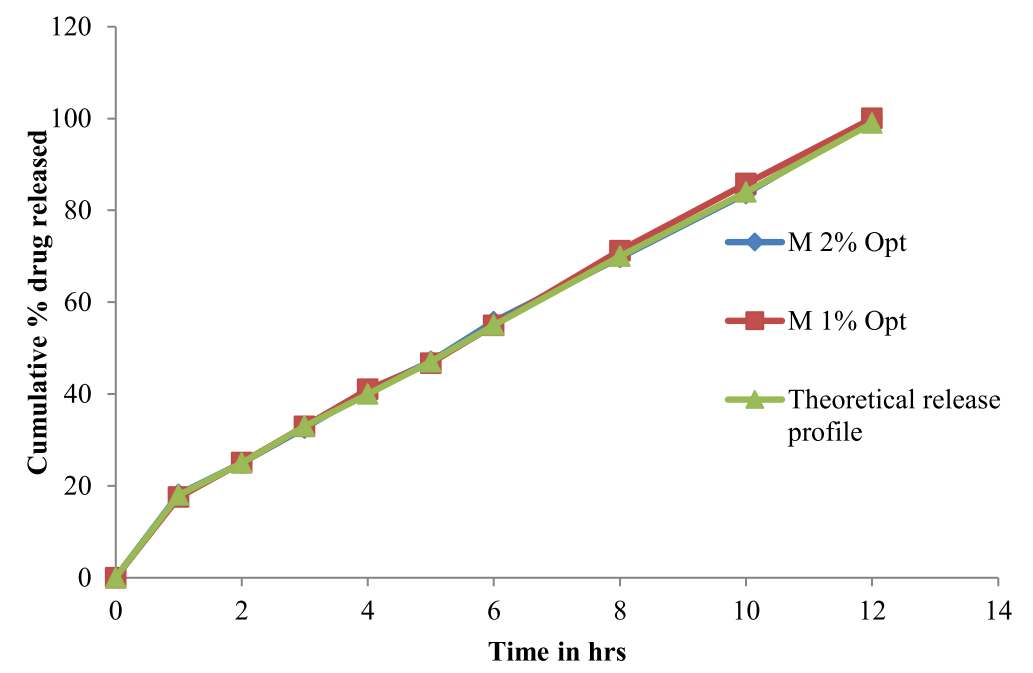

Fig. 8 Comparative dissolution profiles of $\mathrm{M} 2 \%_{\mathrm{opt}}, \mathrm{M} 1 \%_{\mathrm{opt}}$, and theoretical release profile

Upon comparison of the observed responses with that of the anticipated responses, the prediction error was lower than $5.0 \%$ (Table 13).

\section{Drug-polymer interaction studies}

FTIR The FTIR spectra of pure drug Nizatidine, pure polymers Mimosa (2\%), and Mimosa (1\%) and their optimized formulations $M 2 \%_{\text {opt }}$ and $M 1 \%_{\text {opt }}$ are shown in Fig. 9.
The FTIR spectrum of Nizatidine showed peak at $3503.74 \mathrm{~cm}^{-1}$ due to $-\mathrm{OH} ; 3399.82-3372.73,3236.89$ $\mathrm{cm}^{-1}$ due to $-\mathrm{NH}_{2}$ and $-\mathrm{NH}$ respectively, 1446.39$1599.98 \mathrm{~cm}^{-1}$ due to $\mathrm{C}=\mathrm{N}, 694.88-608.86 \mathrm{~cm}^{-1}$ due to $\mathrm{C}-\mathrm{S}, 1326.12 \mathrm{~cm}^{-1}$ due to $\mathrm{S}(=\mathrm{O})_{2}$ asymmetric stretching, $1144.28 \mathrm{~cm}^{-1}$ due to $\mathrm{S}(=\mathrm{O})_{2}$ symmetric stretching confirming the drug structure.

The FTIR spectrum of Mimosa (2\%) showed hydroxyl stretching at $3440.82 \mathrm{~cm}^{-1}$, C-O-C asymmetric stretching at $1289.33 \mathrm{~cm}^{-1}$, and $\mathrm{C}-\mathrm{O}-\mathrm{C}$ symmetric stretching at $1103.89 \mathrm{~cm}^{-1}$.

Table 11 Formulae of optimized EGFMT

\begin{tabular}{|c|c|c|}
\hline Quantity (mg/tablet) ingredients & $M 2 \%_{\text {opt }}$ & $M 1 \%_{\text {opt }}$ \\
\hline Nizatidine & 85.00 & 85.00 \\
\hline $\operatorname{Mimosa}(2 \%)\left(X_{1}\right)$ & 170 & - \\
\hline $\operatorname{Mimosa}(1 \%)\left(X_{1}\right)$ & - & 194.7 \\
\hline Sodium bicarbonate $\left(X_{2}\right)$ & $38.25(15 \%)$ & $29.08(10.4 \%)$ \\
\hline Aerosil & 2.00 & 2.00 \\
\hline Magnesium stearate & 1.00 & 1.00 \\
\hline Total & 296.25 & 312 \\
\hline \multicolumn{3}{|l|}{ Characteristics } \\
\hline FLT (s) & 9.1 & 10.3 \\
\hline SWI & 16.7 & 16.3 \\
\hline$T_{100}$ & 12 & 11.039 \\
\hline TFT (h) & 14 & 13 \\
\hline Uniformity of weight ${ }^{a}(\mathrm{mg})$ & $296.5 \pm 0.67$ & $312 \pm 1.24$ \\
\hline Uniformity of content ${ }^{\mathrm{b}}(\%)$ & $100.09 \pm 0.25$ & $101.04 \pm 1.09$ \\
\hline Hardness ${ }^{c}\left(\mathrm{~kg} / \mathrm{cm}^{2}\right)$ & 4.5 & 4.6 \\
\hline Friability (\%) & 0.09 & 0.01 \\
\hline
\end{tabular}

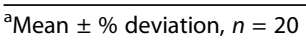

${ }^{b}$ Mean \pm s.d., $n=10$

${ }^{\mathrm{c}}$ Mean, $n=5$ 
Table 12 Correlation coefficient, $f_{1}$, and $f_{2}$ values of optimized EGFMT

\begin{tabular}{lll}
\hline & $\mathbf{M 2}_{\mathbf{o p t}}$ & M1\% \\
\hline Zero-order ' $r$ ' value & 0.9952 & 0.9956 \\
First-order ' $r$ ' value & 0.8684 & 0.8789 \\
Higuchi ' $r$ ' value & 0.9757 & 0.9749 \\
Hixon-Crowell 'r' value & 0.9320 & 0.9041 \\
Korsmeyer-Peppas ' $r$ ' value & 0.9932 & 0.9945 \\
Korsmeyer-Peppas ' $n$ ' value & 0.70 & 0.71 \\
$f_{1}$ & 0.75 & 1.30 \\
$f_{2}$ & 97.84 & 93.58 \\
\hline
\end{tabular}

The FTIR spectrum of $M 2 \%_{\text {opt }}$ showed all the characteristic peaks of Nizatidine with minor shifts indicating the undisturbed drug in the formulation. This spectrum showed alcoholic $-\mathrm{OH}$ stretch at $3504.37 \mathrm{~cm}^{-1},-\mathrm{NH} 2$ and $-\mathrm{NH}$ stretch at 3399.44 and $3236.45 \mathrm{~cm}^{-1}$ respectively; $\mathrm{C}=\mathrm{N}$ stretch at $598.94 \mathrm{~cm}^{-1}, \mathrm{C}-\mathrm{S}$ stretch at 691.88 $\mathrm{cm}^{-1}, \mathrm{~S}(=\mathrm{O})_{2}$ asymmetric and symmetric stretching at $1326.01 \mathrm{~cm}^{-1}$ and $1144.59 \mathrm{~cm}^{-1}$ respectively; and C-O-C asymmetric stretching at $1284.25 \mathrm{~cm}^{-1}$ and C-O-C symmetric stretching at $1113.43 \mathrm{~cm}^{-1}$.

The FTIR spectrum of $\mathrm{M} 1 \%_{\text {opt }}$ showed all the characteristic peaks of Nizatidine with minor shifts in its FTIR spectrum like alcoholic $-\mathrm{OH}$ stretch at $3493.82 \mathrm{~cm}^{-1}$, primary and secondary amine $(-\mathrm{NH} 2$ and $-\mathrm{NH})$ stretch at 3388.42 and $3237.67 \mathrm{~cm}^{-1}$ respectively, $\mathrm{C}=\mathrm{N}$ stretch at $1589.05 \mathrm{~cm}^{-1}, \mathrm{C}-\mathrm{S}$ stretch at $684.45 \mathrm{~cm}^{-1}, \mathrm{~S}(=\mathrm{O})_{2}$ asymmetric and symmetric stretching at $1306.26 \mathrm{~cm}^{-1}$ and $1132.15 \mathrm{~cm}^{-1}$ respectively, C-O-C asymmetric stretching at $1280.28 \mathrm{~cm}^{-1}$ and $\mathrm{C}-\mathrm{O}-\mathrm{C}$ symmetric stretching at $1109.16 \mathrm{~cm}^{-1}$ confirms the undisturbed drug in the formulation.

DSC analysis The DSC thermograms of pure drug Nizatidine, pure polymer Mimosa gum, and optimized formulations $M 2 \%_{\text {opt }}$ and $M 1 \%_{\text {opt }}$ are shown in Fig. 10 .

Nizatidine showed a single sharp endothermic peak at $170.08{ }^{\circ} \mathrm{C}$ corresponding to the melting range of Nizatidine. Mimosa gum showed broad endothermic peaks at $77.35{ }^{\circ} \mathrm{C}$ and $73.43{ }^{\circ} \mathrm{C}$ respectively. Nizatidine melting peak was slightly shifted to left for
$M 2 \%_{\text {opt }}$ and $M 1 \%_{\text {opt }}$ at $168.64{ }^{\circ} \mathrm{C}$ and to $165.71{ }^{\circ} \mathrm{C}$ respectively.

XRD studies X-ray diffractograms of pure drug Nizatidine, polymer Mimosa gum, and their optimized formulations $M 2 \%_{\text {opt }}$ and $M 1 \%_{\text {opt }}$ were shown in Fig. 11 .

X-ray diffraction patterns revealed that pure Nizatidine was clearly in crystalline state as it showed sharp distinct peaks notably at $2 \theta$ diffraction angles of $5.8,11.5,15.8,17.5,18.1,19.2,19.5,20.0,20.5$, $21.0,22.4,22.8,23.2,24.0,24.5,26.2,26.6,27.2$, 30.2 , and $32.2^{\circ}(2 \theta)$.

Pure Mimosa gum showed two distinct sharp peaks at 19.2 and $23.4^{\circ}(2 \theta)$ indicating the crystallinity of the polymers.

Formulation $M 2 \%_{\text {opt }}$ showed characteristic peaks of pure drug without shift at 15.8, 18.1, 19.5, 26.2, 27.2, 30.2 , and $32.2^{\circ}(2 \theta)$ and some new peaks were appeared at 10.6 and $22.3^{\circ}(2 \theta)$. Intensity of the some of the observed peaks are reduced and shifted slightly.

$M 1 \%_{\text {opt }}$ formulation showed characteristic peaks of pure drug, Nizatidine without shift at 18.1, 21.0, 22.4, and $26.6^{\circ}(2 \theta)$. One peak disappeared at $17.5^{\circ}(2 \theta)$ and some peaks showed lower intensity or shifted slightly.

\section{Discussion}

The values of angle of repose [34], bulk density, and compressibility index indicated that the Mimosa gum powder has good flow properties and compressibility.

Table 13 Cross-validation of model obtained using experimental and predicted results of both optimized EGFMT

\begin{tabular}{|c|c|c|c|c|}
\hline Optimized formulation & Response & Predicted value & Experimental value & $\%$ prediction error $^{\mathrm{a}}$ \\
\hline \multirow[t]{3}{*}{$\overline{M 2 \% \text { ОРт }}$} & FLT & 9.1 & 9.3 & -2.19 \\
\hline & SWI & 16.7 & 16.8 & -0.59 \\
\hline & $T_{100}(h)$ & 12 & 12.00 & 0 \\
\hline \multirow[t]{3}{*}{ M1\% OPT } & FLT & 10.3 & 10.34 & -0.38 \\
\hline & SWI & 16.3 & 16.4 & -0.613 \\
\hline & $T_{100}(h)$ & 11.039 & 12.00 & 0.00 \\
\hline
\end{tabular}

${ }^{a}$ Percent error was calculated using the formula: [(predicted value - experimental value)/predicted value] $\times 100$ 


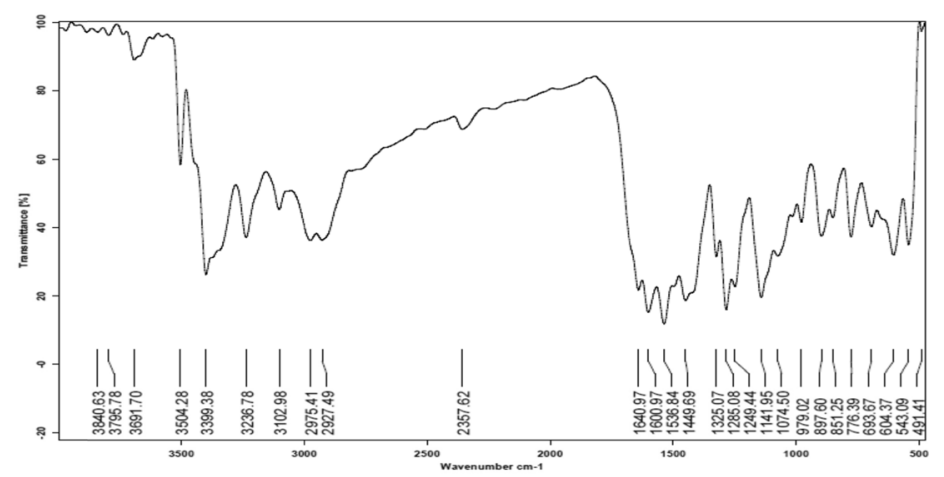

(a)

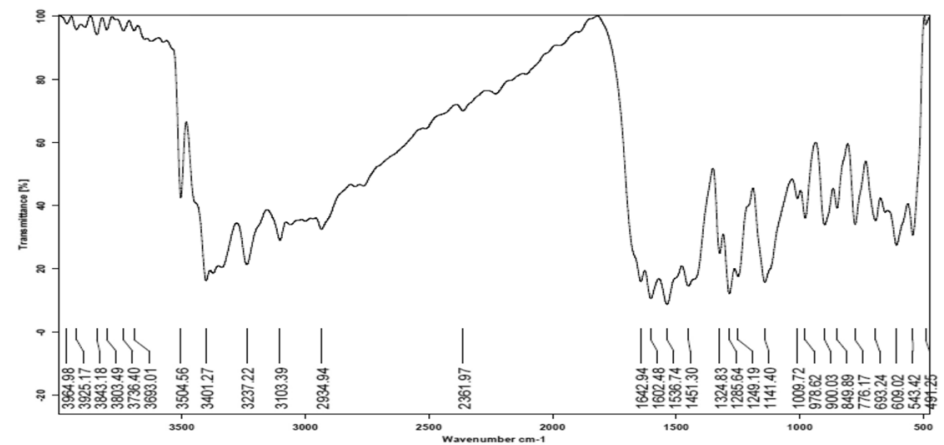

(b)

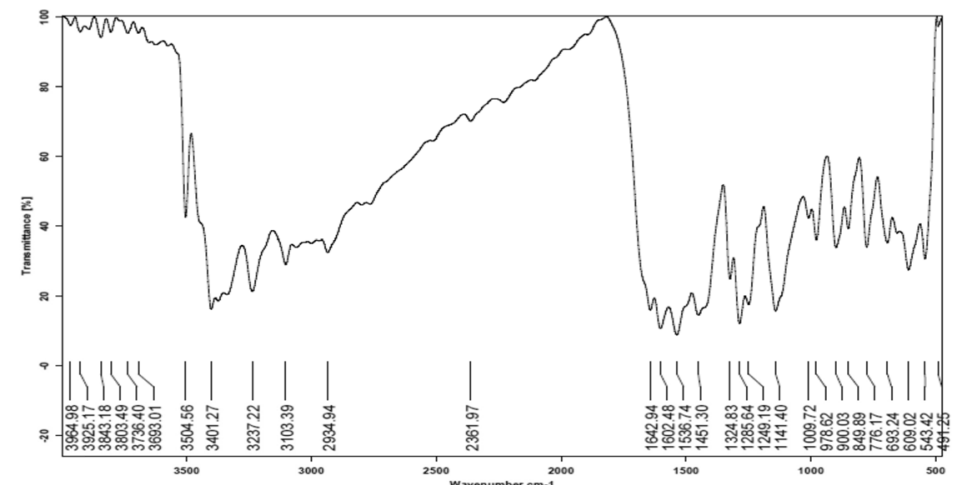

(c)

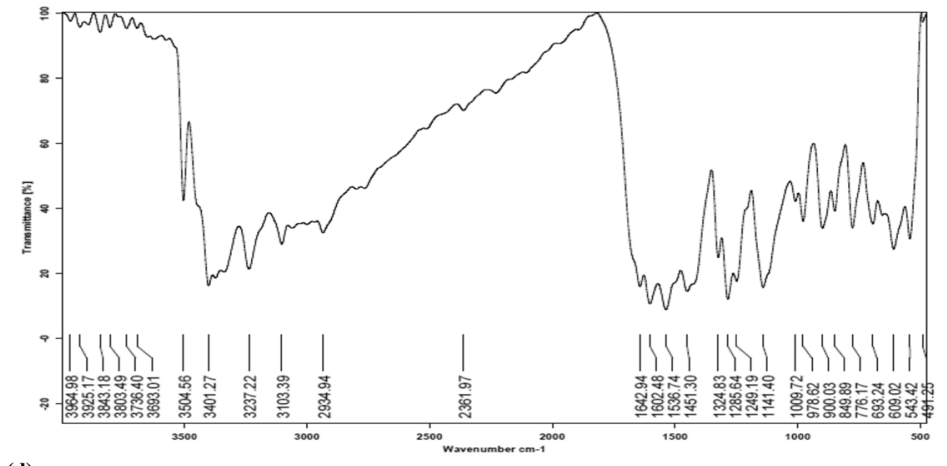

(d)

Fig. 9 FTIR spectra of a Nizatidine, b Mimosa, c M 2\% $\%_{\text {opt, }}$ and d M 1\% opt 

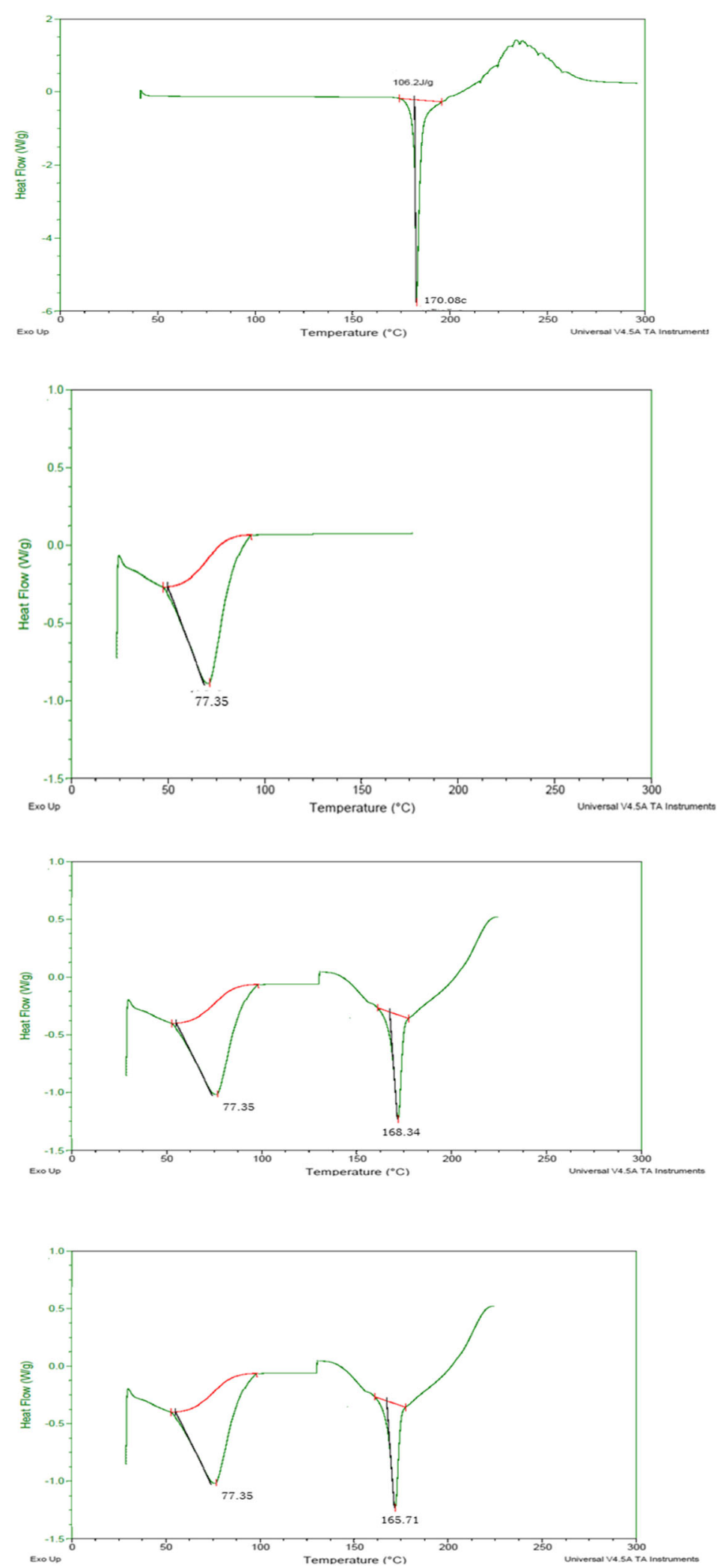

Fig. 10 DSC of a Nizatidine, b Mimosa gum, c M 2\%opt, and d M 1\% 

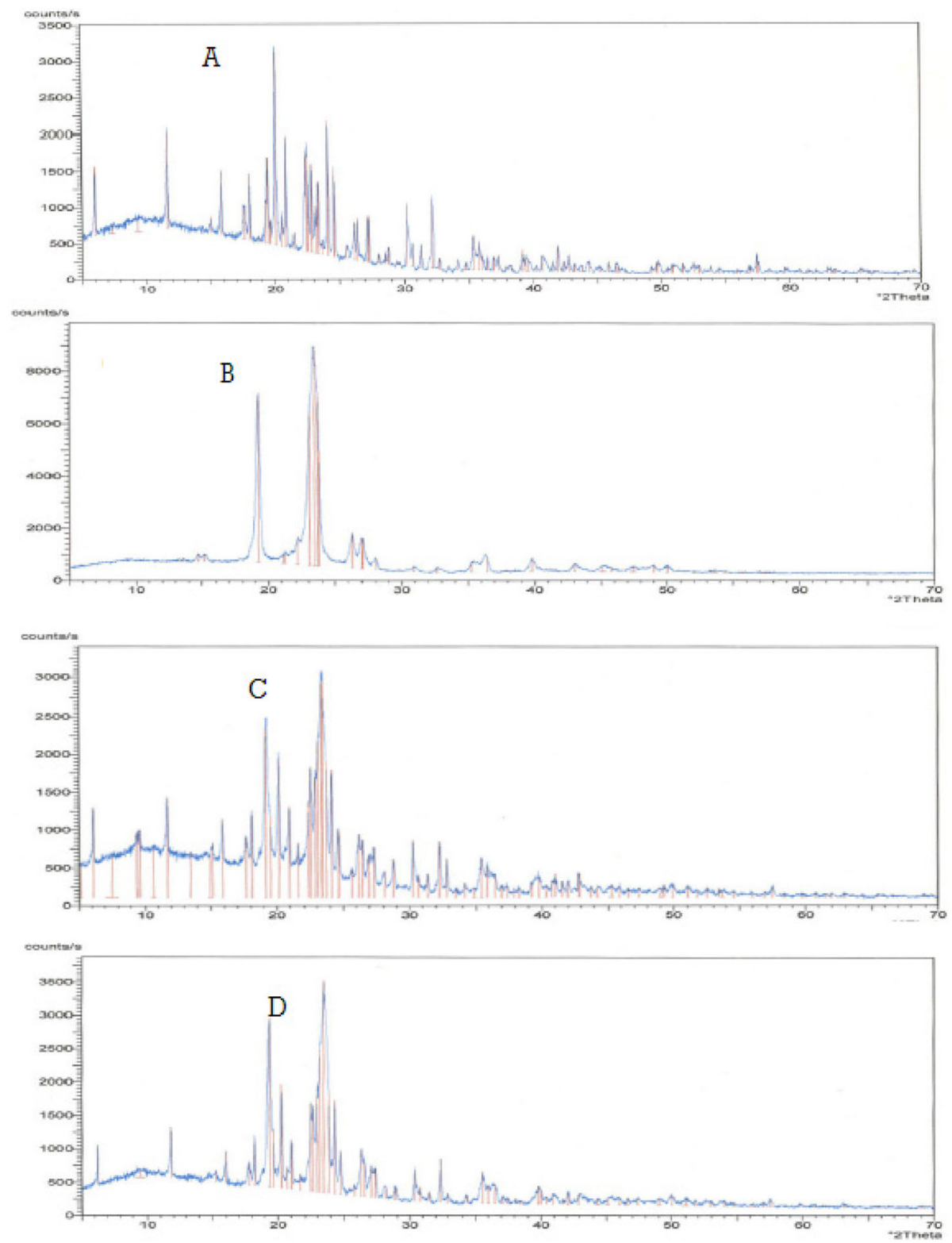

Fig. 11 X-ray diffractograms of a Nizatidine, b Mimosa gum, c M2\% $\%_{\mathrm{opt}}$ and $\mathbf{d} \mathrm{M} 1 \%_{\mathrm{opt}}$

High value of swelling index revealed the high swelling ability of Mimosa gum.

The swelling ability of any polysaccharide depends upon its water retention capacity [35]. The water absorption capacity of Mimosa gum was found to be $19 \mathrm{ml}$. The $\mathrm{pH}$ of the $1 \% \mathrm{w} / \mathrm{v}$ Mimosa gum solution was found to be 4.8 indicating the gum is weakly acidic in nature. Acidic nature of Mimosa gum may be due to the presence of acetyl groups, which is confirmed by the determination of volatile acidity of Mimosa gum. The volatile acidity of Mimosa gum was found to be $17.2 \%$. It was reported that the viscosity of gum is directly proportional to the volatile acidity of gum. Hence, determination of volatile acidity is a useful tool in the evaluation of the quality of the gum with regard to its viscosity.

The angle of repose values of all drug-polymer physical mixtures were found to be $24-33^{\circ}$ indicating the suitability of physical mixtures for direct compression. The floating lag time was increased with increase in the polymer content, whereas decreased with increase in the amount of sodium bicarbonate. This could be due to the entrapment of the generated gas in the polymer hydrogel enabling it to float. These results clearly indicated the influence of the viscosity of the polymer in maintaining the floating of the EGFMT. 
The tablets prepared in each batch were found to have uniformity of weight and the percent deviation was found to be complied with compendial standard for uniformity of weight of the tablets. Hardness values for all the prepared tablets were found to be in the range of 4 to $5 \mathrm{~kg} / \mathrm{cm}^{2}$. Friability test is intended to determine the physical strength of the tablets. The friability values of all the prepared tablets were less than $1 \%$ which indicated that the test was complied with the official compendial tests for tablets as per IP. The content of each individual preparations was found to be within the limits of $85-115 \%$ of the average content indicating the uniformity of content test complies with the official compendial tests for tablets as per IP.

The most important factor influencing the rate of drug release from hydrophilic swellable matrices is drug to polymer ratio. An increase in polymer concentration results in increased viscosity, thicker gel layer with a longer diffusion path. This could cause a decrease in the effective diffusion coefficient of the drug and therefore a reduction in the drug release rate.

Dissolution data indicated that the higher viscosity (or molecular weight) Mimosa (2\%) delayed the drug release for extended period of time up to $23 \mathrm{~h}$ when compared to lower viscosity (or molecular weight) Mimosa (1\%), which controlled the release of the drug up to $12 \mathrm{~h}$ only. This behavior could be explained that polymer particles of increasing viscosity (or molecular weight) will swell rapidly and produce swollen particles of smaller volume. The matrices made of particles with higher viscosity grade will contain pores of smaller diameters due to formation of hydrogel with higher gel strength which will slower drug release than those made up of polymer particles with lower viscosity grade [36].

$T_{100}$ values were found to be increased with increasing the polymer content and viscosity (or molecular weight) and decreased with increasing the amount of sodium bicarbonate. These findings indicated substantially slower release with increase in polymer's viscosity (molecular weight). The hydrogel formed during the penetration of dissolution media into the matrix structure consists of closely packed swollen particles. With further increase in polymer amount, thicker gel forms inhibiting dissolution media penetration resulting significant increase in the values of $T_{100}$.

Increased sodium bicarbonate resulted in relatively higher drug release rates indicated by decreased $T_{100}$ values. The increased amount of sodium bicarbonate caused a large amount of effervescence, which in turn resulted in pore formation, which led to rapid hydration of the polymer matrix and thereby rapid drug release [37].
The significant parameters in the equations can be selected using a stepwise forward and backward elimination for the calculation of regression analysis. However, in the present study, full model having both significant and non-significant $p$ values were used for obtaining dependent variables. Coefficients with one factor indicate the effect of that particular factor, while the coefficients with more than one factor and those with second-order terms represent the interaction between those factors and the quadratic nature of the phenomena, respectively. Positive sign of the term indicates positive (additive) effect, while negative sign indicates negative (antagonistic) effect of the factor on the response.

Main effects of all the selected independent variables like polymer quantity $\left(\mathrm{X}_{1}\right)$ and \% w/w of sodium bicarbonate $\left(X_{2}\right)$ are highly significant $(p<0.05)$.

Negative and additive effects were observed respectively for polymer $\left(X_{1}\right)$ and sodium bicarbonate $\left(X_{2}\right)$ in case of FLT indicating the increased time with increased polymer content and increased sodium bicarbonate concentration. Swelling index at $1 \mathrm{~h}$ indicating the decreased swelling with increased polymer content and increased sodium bicarbonate concentration, whereas reverse situation was observed for $T_{100}$ values, i.e., additive and negative effects for respectively polymer and sodium bicarbonate. This indicated the influence of both polymer and sodium bicarbonate concentrations in achieving the desired drug release, floating lag time, and swelling index.

The variance of inflation factor 5 (VIF) measures the extent to which the variance of particular model coefficient is inflated by the lack of orthogonality in the design [38]. The VIF values for all the models were found to be one, indicating good estimation of coefficient.

From the contour plots, it was observed that increase in the polymer (X1) from 85 to $170 \mathrm{mg}$ and later to 255 mg increased FLT, decreased SWI, and increased $T_{100}$, i.e., retarded the release of Nizatidine from matrix tablets. This could be due to the increase in resistance of the gel layer to drug dissolution and gel erosion. At a higher polymer level, formation of tightly swollen gel layer caused by more intimate contact in between the particles of Mimosa resulted in decreased mobility of insoluble drug particles in swollen matrices, which lead to decreased release rate.

Additionally, increasing the sodium bicarbonate $\left(X_{2}\right)$ from 10 to $15 \%$ and then to $20 \%$ decreased FLT, increased SWI, and decreased $T_{100}$, i.e., enhanced the release of Nizatidine from matrix tablets. The increased amount of sodium bicarbonate caused a large amount of effervescence, which in turn resulted in pore formation, leading to rapid hydration of the polymer matrix and thereby decreased FLT. 
The optimized formulation of Mimosa gum (2\%) (M2\%opt) contained $170 \mathrm{mg}$ of polymer and $25.5 \mathrm{mg}$ (15\%) of sodium bicarbonate. Similarly, the optimized formulation of Mimosa (1\%) (M1\%opt) contained 255 $\mathrm{mg}$ of polymer and $34 \mathrm{mg}(10 \%)$ of sodium bicarbonate.

The predicted formulations were prepared and compared their dissolution profile with the theoretical profile. The optimized formulations were very close to ' 0 ' $(<2)$ and $f_{2}$ values were more than ' 50 ' $(>90)$ indicating the similarity between the optimized formulations and theoretical profile. The results clearly indicated that the optimized formulations followed zero order release kinetics with diffusion mechanism as per the predicted theoretical release rate confirming the suitability of the predicted theoretical release profile.

Lower values of the relative error indicated that there was a close agreement of experimental values with predicted values for both the polymers. This proved the predictability and validity of model and ascertained the effects of polymer and the amount of sodium bicarbonate on drug release.

The FTIR spectra of $M 2 \%_{\text {opt }}$ and $M 1 \%_{\text {opt }}$ showed all the characteristic peaks of Nizatidine confirms the undisturbed drug in the formulation.

Compared to pure drug, the melting peak was broadened to some extent in the formulations which may be due to changes in crystalline form. In addition, the studied polymers were hydrophilic in nature with melting points less than that of Nizatidine. The low melting point of the polymers might have influenced the shift in the melting point of drug in the formulation.

\section{Conclusion}

GRDDS of Nizatidine was prepared using Mimosa gum $1 \%$ and $2 \%$ as rate retarding polymer. The results clearly indicated that the optimized formulations followed zeroorder release kinetics with diffusion mechanism as per the predicted theoretical release rate confirming the suitability of the predicted theoretical release profile.

\section{Abbreviations}

GRDDS: Gastroretentive drug delivery systems; RSM: Response surface methodology; DSC: Differential scanning calorimetry; EGFMT: Effervescent gastric floating matrix tablets; FLT: Floating lag time; TFT: Total floating time; DE: Dissolution efficiency; MDT: Mean dissolution time; XRD: X-ray diffraction

\section{Acknowledgements}

The authors express their sincere thanks to the management of Acharya Nagarjuna University, Guntur and Chebrolu Hanumaiah institute of Pharmaceutical sciences, Guntur, Andhra Pradesh, India and Aditya Pharmacy College, Surampalem, Andhra Pradesh for providing necessary facilities to carry out the above research work

\section{Authors' contributions}

We declare that this work was done by the authors named in this article: MLS conceived and designed the study and carried out the laboratory work, analyzed the data, and drafted the manuscript. RBJ supervised the work assisted in the data analysis. All authors have read and approved the final manuscript.

\section{Funding}

The authors have no funding to report.

\section{Availability of data and materials}

All necessary data generated or analyzed during this study are included in this published article. Any additional data could be available from corresponding author upon request.

Ethics approval and consent to participate

Not applicable.

\section{Consent for publication \\ Not applicable.}

\section{Competing interests}

The authors declare that they have no conflict of interest.

\section{Author details}

'Department of Pharmaceutics, ANU College of Pharmaceutical Sciences, Acharya Nagarjuna University, Nagarjuna Nagar, Guntur 522510, India. ${ }^{2}$ Department of Pharmaceutics, Chebrolu Hanumaiah Institute of Pharmaceutical Sciences, Chowdavaram, Guntur 522019, India.

Received: 1 April 2020 Accepted: 5 November 2020

Published online: 07 January 2021

\section{References}

1. Jain A, Pandey V, Ganeshpurkar A, Dubey N, Bansal D (2015) Formulation and characterization of floating microballoons of nizatidine for effective treatment of gastric ulcers in murine model. Drug Deliv 22:306-311

2. Anilkumar A, Murthy TE, Rani AP (2020) Design and development of ondansetron hydrochloride $\mathrm{pH}$ independent control released matrix tablets. Pak J Pharm Sci 33(2):567-573

3. Badhan AC, Mashru RC, Shah PP, Thakkar AR, Dobaria NB (2009) Development and evaluation of sustained release gastroretentive minimatrices for effective treatment of $\mathrm{H}$. pylori infection. AAPS PharmSciTech 10:459-467

4. Kumari SD, Vengatesh S, Elango K, Damayanthi RD, Deattu N, Christina P (2012) Formulation and evaluation of floating tablets of ondansetron hydrochloride. Int J Drug Dev Res 4(4):265-274

5. Genest S, Kerr C, Shah A, Rahman MM, Saif-E-Naser GM, Nigam P (2008) Comparative bioactivity of two mimosa species. Lat Am Caribb Bull Med Aromat Plants 7:38-43

6. Ueda M, Yamamura S (1999) The chemistry of leaf movement in Mimosa pudica L. Tetrahedron. 55:10937-10948

7. Yadav P, Singh K (2013) Mimosa pudica seed mucilage: Isolation; characterization and evaluation as tablet disintegrant and binder. Int. J. Bio. Macro. 57:105-110.

8. Naresh G., Narayan P. (2013) Pharmaceutical applications of various natural gums, mucilages and their modified forms.Carbohydrate Polymers. 92 2: 1685-1699.

9. Deniz B, Ismail H (2007) Modeling and optimization I: usability of response surface methodology J. of food Eng. 78 3: 836-845.

10. Kuo PH, Zhang BC (2017) Application of two-level factorial design to investigate the effect of process parameters on the sonocrystallization of sulfathiazole. J Cryst Growth 471:8-14

11. Müller ALH (2020) Design of experiments and method development. SolidPhase Extraction 10:589-608

12. Ahmad H, Sehgal S, Mishra A, Gupta R (2012) Mimosa pudica L. (Laajvanti): an overview. Pharmacogn Rev 6(12):115-124

13. Madan, J.R.; Kamate, V.J.; Dua, K.; Awasthi A, R (2017) Improving the solubility of nevirapine using a hydrotropy and mixed hydrotropy based solid dispersion approach. Polim Med 47: 83-90.

14. Jiménez-Castellanos MR, Zia H, Rhodes CT (1994) Design and testing in vitro of a bioadhesive and floating drug delivery system for oral application. Int J Pharm 105:65-70

15. IP2007: Uniformity of weight of single-dose preparations. The Indian Pharmacopoeia Commission, Ghaziabad, India. Vol 1: 182, 2008.

16. Banker GS, Anderson NR (2009) Tablets, in Lachman L, Lieberman HA and Kanig JL: the theory and practice of industrial pharmacy. CBS publishers \& distributors, New Delhi, pp 293-345 
17. IP2007: Friability of uncoated tablets. The Indian Pharmacopoeia Commission, Ghaziabad, India. Vol. I: 183, 2008

18. Shah VP, Polli JE (1996) Methods to compare dissolution profiles. Drug Inf J 30:1113-1120

19. Ruben M (2008) A new principal component analysis-based approach for testing "similarity" of drug dissolution profiles. Eu J of Pharm Sci 34(1):66-77

20. Zhang Y, Huo M (2010) An add-in program for modeling and comparison of drug dissolution profiles. AAPS J 12:263-271

21. Berry MR, Likar MD (2007) Statistical assessment of dissolution and drug release profile similarity using a model-dependent approach. J Pharm Biomed Anal 45:194-200

22. Hiba Al, Alison A (2010) To enhance dissolution rate of poorly water-soluble drugs: Glucosamine hydrochloride as a potential carrier in solid dispersion formulations Colloids and Surfaces B: Biointerfaces 76 1: 170-178.

23. Varshosaz J, Talari $R$ (2008) Dissolution enhancement of gliclazide using in situ micronization by solvent change method. Powder Technol 187(3):222-230

24. Jantratid E, Janssen N (2008) Dissolution media simulating conditions in the proximal human gastrointestinal tract: an update. Pharm Res 25(7):1663-1676

25. Vanitha K. Venkataswamy M (2018) Formulation development and evaluation of Mebeverine extended release pellets. Asian J Pharm Tech 2018; 8 (2):71-77.

26. Wagner JG (1969) Interpretation of percent dissolved-time plots derived from in vitro testing of conventional tablets and capsules. J Pharm Sci 58: 1253-1257

27. Higuchi T (1963) Mechanism of sustained-action medication. Theoretical analysis of rate of release of solid drugs dispersed in solid matrices. J Pharm Sci 52:1145-1149

28. Katzhendler I, Hoffman A, Goldberger A, Friedman M (1997) Modeling of drug release from erodible tablets. J Pharm Sci 86:110-115

29. Korsmeyer RW, Gurny R, Doelker E, Buri P, Peppas NA (1983) Mechanisms of solute release from porous hydrophilic polymers. Int J Pharm 15:25-35

30. Ritger PL, Peppas NA (1987) A simple equation for description of solute release II. Fickian and anomalous release from swellable devices. J Control Release 5:37-42

31. Khuri Al, Cornell JA (1987) Response surface design and analysis. Marcel Dekker Inc., New York

32. Srikanth MV, Rao NS, Sunil SA, Ram BJ, Kolapalli VR (2012) Statistical design and evaluation of propranolol $\mathrm{HCl}$ gastric floating tablet. Acta Pharm sinica B 42(1):60-69

33. Jgade SC, Patil S and Kuchekar BS (2013) Application of design of experiment for floating drug delivery of Tapentadol hydrochloride. Computational and mathematical methods in medicine.

34. Jonat S, Albers P, Gray A, Schmidt PC (2006) Investigation of the glidant properties of compacted colloidal silicon dioxide by angle of repose and $X$ ray photoelectron spectroscopy. Eur J Pharm Biopharm 63(3):356-359

35. Vasantha PV, Puratchikody A, Mathew ST, Balaraman AK (2011) Development and characterization of Eudragit based mucoadhesive buccal patches of salbutamol sulfate. Saudi Pharm J 19:207-214

36. Choudhary M, Salukhe T, Ganeshpurkar A, Pandey V, Dubey N, Bansal D (2015) Formulation and evaluation of sustained release matrix tablets of pioglitazone hydrochloride using processed Aloe vera mucilage as release modifier. Drug Dev Ther 6:5-10

37. Larocque G, Arnold AA, Chartrand E, Mouget Y, Marcotte I (2010) Effect of sodium bicarbonate as a pharmaceutical formulation excipient on the interaction of fluvastatin with membrane phospholipids. Eur Biophys 39(12):1637-1647

38. Marcoulides KM, Raykov T (2019) Evaluation of variance inflation factors in regression models using latent variable modeling methods. Educ Psychol Meas 79(5):874-882

\section{Publisher's Note}

Springer Nature remains neutral with regard to jurisdictional claims in published maps and institutional affiliations.

\section{Submit your manuscript to a SpringerOpen ${ }^{\circ}$ journal and benefit from:}

- Convenient online submission

- Rigorous peer review

- Open access: articles freely available online

- High visibility within the field

- Retaining the copyright to your article

Submit your next manuscript at $\boldsymbol{\nabla}$ springeropen.com 